\title{
The Complexity of Urban Eco-evolutionary Dynamics
}

\author{
MARINA ALBERTI, ERIC P. PALKOVACS, SIMONE DES ROCHES, LUC DE MEESTER, KRISTIEN I. BRANS, \\ LYNN GOVAERT, NANCY B. GRIMM, NYEEMA C. HARRIS, ANDREW P. HENDRY, CHRISTOPHER J. SCHELL, \\ MARTA SZULKIN, JASON MUNSHI-SOUTH, MARK C. URBAN, AND BRIAN C. VERRELLI
}

\begin{abstract}
Urbanization is changing Earth's ecosystems by altering the interactions and feedbacks between the fundamental ecological and evolutionary processes that maintain life. Humans in cities alter the eco-evolutionary play by simultaneously changing both the actors and the stage on which the eco-evolutionary play takes place. Urbanization modifies land surfaces, microclimates, habitat connectivity, ecological networks, food webs, species diversity, and species composition. These environmental changes can lead to changes in phenotypic, genetic, and cultural makeup of wild populations that have important consequences for ecosystem function and the essential services that nature provides to human society, such as nutrient cycling, pollination, seed dispersal, food production, and water and air purification. Understanding and monitoring urbanizationinduced evolutionary changes is important to inform strategies to achieve sustainability. In the present article, we propose that understanding these dynamics requires rigorous characterization of urbanizing regions as rapidly evolving, tightly coupled human-natural systems. We explore how the emergent properties of urbanization affect eco-evolutionary dynamics across space and time. We identify five key urban drivers of change-habitat modification, connectivity, heterogeneity, novel disturbances, and biotic interactions-and highlight the direct consequences of urbanization-driven eco-evolutionary change for nature's contributions to people. Then, we explore five emerging complexities-landscape complexity, urban discontinuities, socio-ecological heterogeneity, cross-scale interactions, legacies and time lags-that need to be tackled in future research. We propose that the evolving metacommunity concept provides a powerful framework to study urban eco-evolutionary dynamics.
\end{abstract}

Keywords: adaptation, urban ecology, eco-evolutionary dynamics, coupled human-natural systems, metacommunities

$\mathbf{U}$ rbanization is changing Earth's ecosystems and altering the regional and global distribution and abundance of species. Humans in cities modify landscapes and microclimates, restructure connectivity among habitat patches, alter food webs, change species composition, initiate novel species interactions, and reshape competition, predation, and symbioses (Pickett et al. 2001, Alberti 2008, Grimm et al. 2008). These ecological changes can cause evolutionary change by altering natural selection, neutral genetic change, or gene flow, leading to species trait changes that could further alter ecological dynamics (Palkovacs et al. 2012, Alberti 2015). By changing the ecological theatre, cities are simultaneously changing both the actors and the stage, thereby writing a new eco-evolutionary play (Hutchinson 1965).

With the emergence of global urbanization, humans-as agents of niche construction-have achieved a new capacity to shape the ecological and evolutionary forces that drive biodiversity (Odling-Smee et al. 2013, Boivin et al. 2016). By building their own ecological niche, humans have transformed both their own environment and those of other species, generating complex feedbacks in both ecological and evolutionary processes (Palkovacs and Post 2009, Start et al. 2019). Although humans have been altering ecological processes for millennia, urbanization represents a major shift in intensity, speed, and scale (Ellis 2015). However, the eco-evolutionary consequences of human-driven niche construction have only recently been recognized (Palkovacs et al. 2012).

Urban development modifies landscape structure (e.g., loss of forest cover and connectivity) and processes (e.g., biogeochemical cycling), and significantly alters biotic interactions (e.g., predation), thereby changing species composition and community dynamics. The resulting changes in selection pressures can cause shifts in ecologically relevant traits that can influence ecological interactions and ecosystem stability (Alberti et al. 2017a, Dakos et al. 2018). Cities are hotspots for contemporary evolutionary change that occurs via alterations in the distribution of genetic diversity, changing allele frequencies that might translate into phenotypic trait changes (physiology, morphology, behavior, and life history). Trait changes can affect demographic rates (such as reproduction, survival, or dispersal) and, in turn, shape population dynamics (e.g., numbers of individuals and population persistence), community structure (e.g., species diversity and composition), and ecosystem function

BioScience XX: 1-22. (C) The Author(s) 2020. Published by Oxford University Press on behalf of the American Institute of Biological Sciences. All rights reserved. For Permissions, please e-mail: journals.permissions@oup.com.

doi:10.1093/biosci/biaa079 
Urban-eco-evolutionary framework

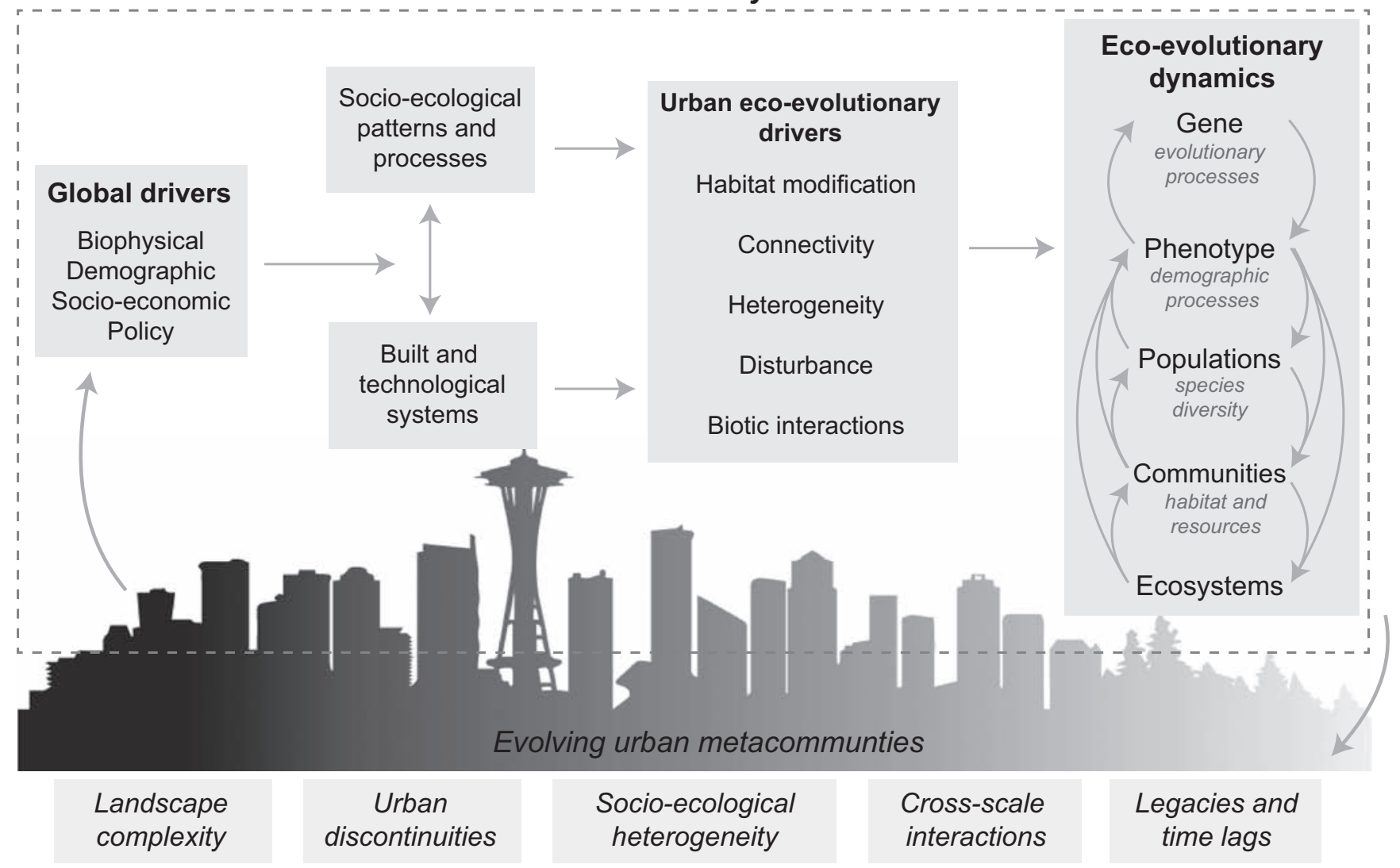

Figure 1. Conceptual framework of urban eco-evolutionary dynamics. Drivers of evolutionary change in urbanizing regions include habitat modification, connectivity, temporal and spatial heterogeneity, novel disturbances, and biotic interactions. Urbanization affects the balance between evolution and extinction by altering dispersal and genetic diversity, creating cascading effects across all levels of biological organization. Changes in allele frequencies might translate into phenotypic trait changes (physiology, morphology, behavior, and life history) that affect demographic rates (e.g., reproduction, survival, or dispersal) and ultimately population dynamics (e.g., numbers of individuals and population persistence), community structure (e.g., species richness or diversity), and ecosystem function (e.g., nutrient cycling, decomposition, and primary productivity). These changes can cascade among levels of ecological organization and ultimately affect evolution.

(e.g., nutrient cycling, decomposition, and productivity; figure 1).

Although evidence of contemporary evolutionary change (Fussmann et al. 2007, Post and Palkovacs 2009, Schoener 2011, Hendry 2016, Szulkin et al. 2020) and its implications for ecosystem function is rapidly increasing (Post and Palkovacs 2009, Whitehead et al. 2010, Hendry 2016), the predominant views of biodiversity and ecosystem function that inform current strategies to achieve sustainability are still fundamentally static. In the present article, we show how the rapid evolutionary changes driven by urbanization have the potential to affect species persistence and ecosystem functions with important consequences for the delivery of nature's contributions to people (box 1; Díaz et al. 2018). We argue that understanding the complex ecoevolutionary dynamics of urbanization and its influence on stability and biodiversity is central to inform sustainability strategies (Palkovacs and Post 2009). Cities provide natural laboratories to study eco-evolutionary dynamics (see the glossary). However, understanding these dynamics requires a rigorous characterization of urbanizing regions as coupled human-natural systems and their interactions across spatial and temporal scales (Brunner et al. 2019, Hendry 2019, De Meester et al. 2019).

Observations of trait changes across multiple taxa in urban environments provide important clues about the mechanisms linking urbanization to evolutionary change. Several reviews of observed urbanization-driven trait changes have been published over the last decade (Palkovacs et al. 2012, Donihue and Lambert 2015, McDonnell and Hahs 2015, Alberti et al. 2017a, Johnson and Munshi-South 2017, Rivkin et al. 2019). However, the development of a theory of urban eco-evolutionary dynamics requires a unified conceptual framework. Such a framework should draw on advancements in eco-evolutionary theories to support the design of long-term, multicity experiments across a broad 


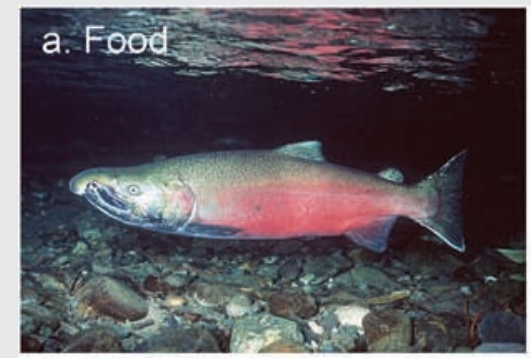

b. Nutrient accumulation

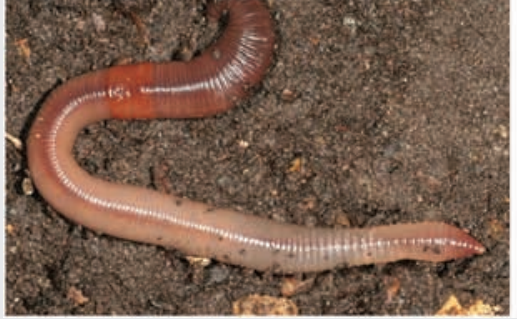

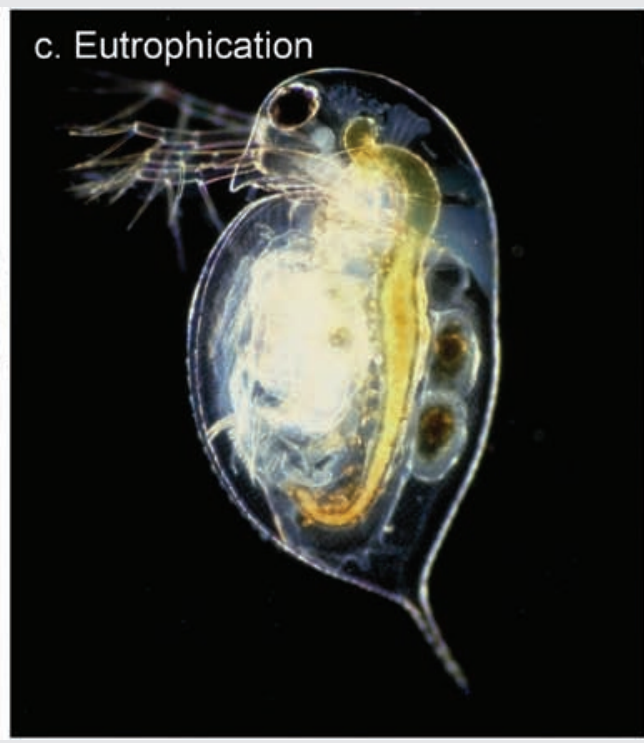
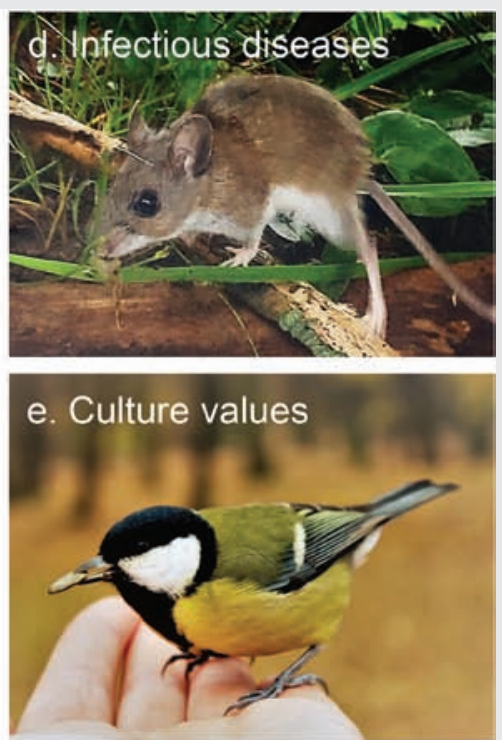

Urbanization-driven trait changes have the potential to affect human wellbeing by altering nature's contributions to people, including food production, primary productivity, pollution control, spread of infectious diseases, and cultural values. Pacific salmon (Oncorhynchus spp.) have evolved smaller body sizes (Carlson et al. 2011). Earthworms (Lumbricus rubellus) are well able to tolerate contaminants in soil (Kille et al. 2013). The water flea Daphnia has adapted to cyanobacteria (Hairston et al. 2001, Ger et al. 2014), thermal environments (Brans et al. 2017b 2017a), and road salt (Coldsnow et al. 2016). The white-footed mouse (Peromyscus leucopus), a common resident of New York City's forest fragments, carries the bacteria for Lyme disease and exhibits signatures of directional selection (Munshi-South et al. 2016). Great tits (Parus major) show significant but contrasting effects of urbanization on genomewide genetic diversity and structure (Björklund et al. 2010, Perrier et al. 2018). Photographs: (a) Ernest Keeley, (b) Malcom Storey, (c) Pul Hebert, (d) Linelle Abueg, (e) Michela Corsini

range of taxa to understand the convergence and divergence of genetic and phenotypic responses. Trait shifts in urban environments across diverse taxa are likely a result of both adaptive changes in allele frequencies (evolution) and phenotypic plasticity (Palkovacs and Hendry 2010). However, most studies that document observations of urbanizationinduced phenotypic changes do not establish the genetic basis of these changes. In addition, observations are often limited to individual cities and to single species (Donihue and Lambert 2015, Johnson and Munshi-South 2017).

Theoretical models of eco-evolutionary feedbacks provide a useful framework for investigating urban eco-evolutionary interactions, but simplifying assumptions and generalizations over many dimensions may bias predictions (Govaert et al. 2019). For example, ecological and evolutionary responses to climate change show varying results when introducing eco-evolutionary feedbacks, multiple species, and spatial interactions. In particular, most current models focus on a single species (Urban et al. 2012); ignore species interactions, trophic interactions (Mellard et al. 2015), and food webs (Rossberg et al. 2006, Bolchoun et al. 2017); disregard interactions across space and the regional dynamics of linked communities (Urban et al. 2012, De Meester et al.
2019); and do not consider eco-evolutionary dynamics over deep time scales (Weber et al. 2017).

A framework for studying urban eco-evolutionary dynamics should be trait-based (functionally linking individual organisms with community structure and dynamics), should be spatially explicit (representing spatially dependent population dynamics), and should include intra- and interspecific interactions within and across trophic levels (Brans et al. 2020). The evolving metacommunity concept and its application through individual-based models have the potential to integrate these complexities (Govaert et al. 2019). A metacommunity is a set of local communities linked by the dispersal of multiple potentially interacting species. The evolving metacommunity framework also assumes that genetically determined trait variation within populations of each species can modify their responses to local environments and interspecific interactions such that ecological and evolutionary processes of selection, dispersal, gene flow, and diversification operate jointly and sometimes nonadditively (Urban and Skelly 2006, Urban et al. 2008, Leibold et al. 2019). Because ecological and evolutionary processes jointly affect trait change in populations and communities, it is also important to partition their separate contributions 


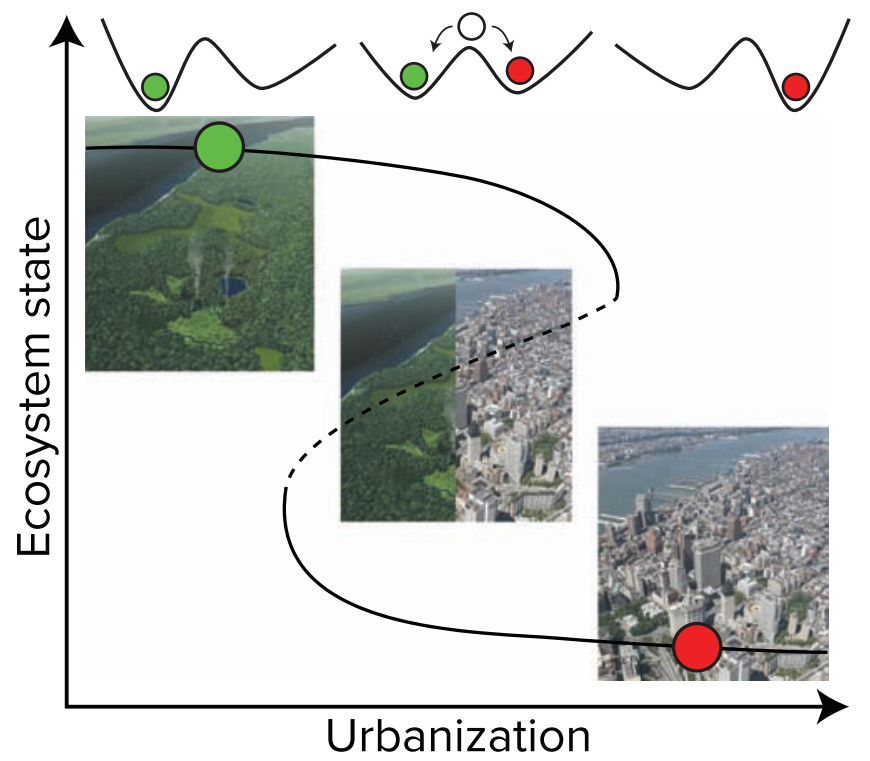

Figure 2. Urban discontinuities. Urbanization represents a discontinuity in the dynamic of ecological systems. As a region urbanizes, ecosystem function declines. The system moves along the upper continuous line until a threshold is reached and the system becomes unstable (dashed portion of curve). As urbanization increases multiple stressors modify ecosystem dynamics and reduce ecosystem function until reaching a point where the system flips into a new state, governed by new dynamics and feedbacks. The system shift can cascade across the levels of ecological organization and affect the eco-evolutionary dynamic. For example, increasing temperature and nutrient loading in urban lakes pose increasing selection pressure on zooplankton behavioral and physiological traits that improve tolerance to cyanobacteria (Ger et al. 2014). Variation in a response trait (e.g., tolerance of zooplankton to cyanobacteria) affects tipping points of urban shallow lakes that can shift their state to a eutrophic state (Dakos et al. 2019). Photographs: Mannahatta Project, Eric Sanderson.

to community structure and ecosystem function using ecoevolutionary partition metrics (Govaert et al. 2016).

An urban eco-evolutionary framework should carefully account for urban complexity. Despite an increased attention to anthropogenic drivers, current perspectives in urban evolution and eco-evolutionary dynamics make relatively simple assumptions about how the urban human-natural system is structured in time and space. In most models (Govaert et al. 2019) and empirical studies (Johnson and Munshi-South 2017), human activity is considered to be an external driver operating along a continuous disturbance gradient, and the ecological and evolutionary responses to urbanization are assumed to remain constant across time and space. Urbanization is frequently reduced to a few aggregated variables (e.g., impervious surface, human population density), which typically do not capture the full urban heterogeneity, variable activities and impacts, and cross-scale interactions among multiple agents of change (Szulkin et al. 2020).

The reality of urbanization is more complex (Alberti 2015, Alberti et al. 2017a). Urbanization represents a discontinuity - a system transition between two alternative states along a continuum of anthropogenic change (figure 2; Alberti 2008). Urban ecosystems exhibit habitat characteristics, spatial and temporal heterogeneity, connectivity, disturbance, and biotic interactions that are distinct from the original ecosystems (figure 3). These system-level properties emerge from complex interactions among heterogeneous human agents and ecosystem processes operating at multiple scales (figure 4; McDonnell and Hahs 2015, Alberti 2016). Urban ecologists have uncovered cities' unique patterns of ecological succession, water flow regimes, soil properties, nutrient cycles, and distinct signatures of biotic interactions and species diversity (Pickett et al. 2001, Alberti 2008, Grimm et al. 2008, McPhearson et al. 2016), but only recently have we begun to understand how these properties change the dynamics between adaptation and the relative abundance of different species (cf. species sorting) that determine species persistence and extinction and therefore shape emergent patterns of biodiversity. Although growing evidence suggests that ecosystem transitions affect and are affected by species trait variation and evolutionary change (Dakos et al. 2018), the causes and feedbacks are particularly difficult to disentangle in urban settings (Alberti 2015, Hendry et al. 2017, Des Roches et al. 2018). In urban settings, rapid evolution and ecological feedbacks may result from multiple selection pressures operating simultaneously, increasing both the total strength of selection on a given trait and the selection on a greater number of traits (Alberti et al. 2017a).

We believe that it is critical to take into account the complexity of urban systems and the heterogeneity of emergent patterns of urbanization for advancing our understanding of eco-evolutionary dynamics and their feedbacks. Despite their commonalities, cities are highly diverse in physical structure, human population density, social heterogeneity, social institutions, and biophysical environments, reflecting different levels of development, history, culture, demographics, economic structure, and infrastructure (Szulkin et al. 2020). This results in variable types and levels of disturbances and multidimensional gradients. The capacity of different organisms to cope and adapt to urban environments varies greatly across different disturbance gradients depending on species-specific dispersal ranges, generation times, standing genetic variation, and trophic positions. Factoring in urban complexity is key to predicting how biodiversity will respond to rapid environmental change, generating new insights for conservation and urban planning (Kinnison et al. 2015).

\section{Drivers of urban eco-evolutionary dynamics}

Global urban biodiversity is a product of the interactions among multiple urban and natural agents that affect 


\section{a. Habitat modification}

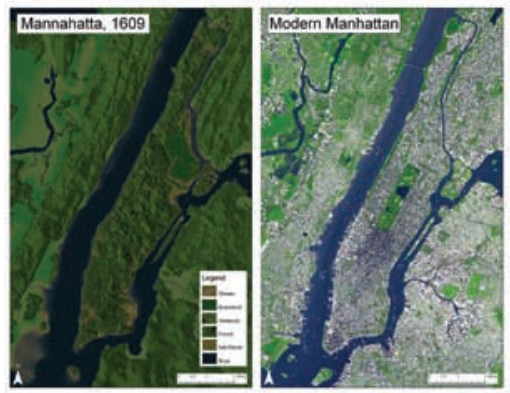

d. Novel disturbances

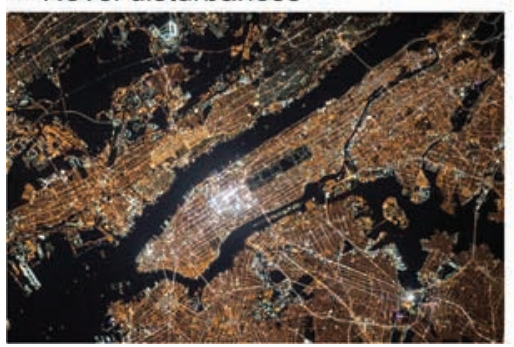

b. Connectivity

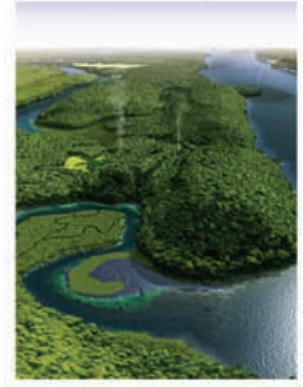

e. Biotic interactions

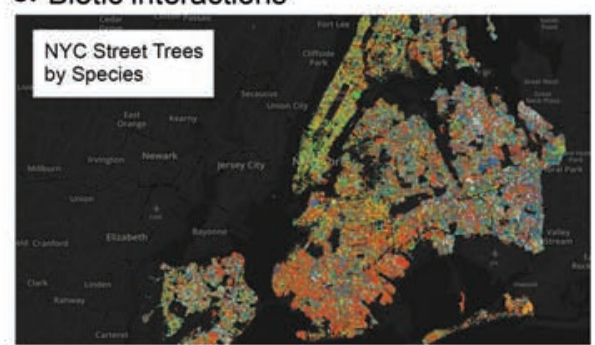

c. Heterogeneity

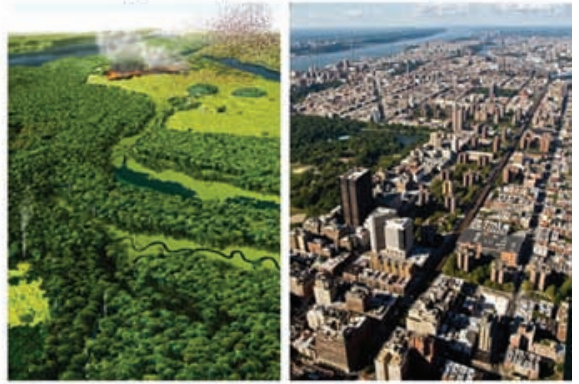

f. Scale

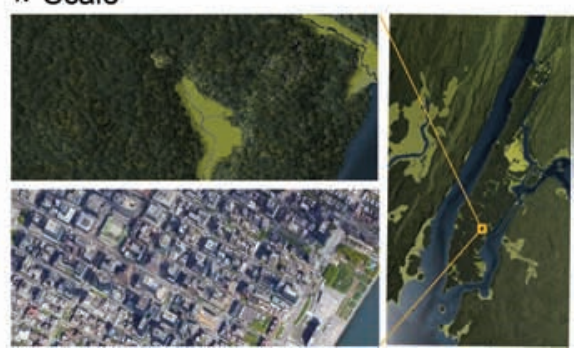

Figure 3. Drivers of eco-evolutionary change in urban environments are emergent properties of interacting socio-ecological systems. Habitat modification due to land cover change leads to loss and configuration changes of natural habitats. The building of dams has been a major driver of loss of hydrological connectivity. Dam removal projects are restoring the hydrological connectivity of rivers and streams. Green infrastructure as constructed habitats and corridors shapes landscape heterogeneity in cities. Novel disturbances such as artificial light at night can influence circadian rhythms and migrations of birds. Human mobility mediates species dispersal and increases the chance of species introduction that drive biotic interactions. Photographs: $(a-c)$ and $(f)$ Welikia Project, Eric Sanderson; (d) NASA; (e) Jill Hubley.

eco-evolutionary dynamics across levels of biological organization (figure 1). The key drivers that shape urban evolutionary dynamics include habitat modification, connectivity, spatial and temporal heterogeneity, novel disturbances, and biotic interactions (figure 3). Although these drivers of evolutionary change characterize most anthropogenic systems, their intensity, spatial cooccurrence, and time compression in urban environments set urbanization-driven eco-evolutionary dynamics apart from those of other anthropogenic contexts.

Driver 1: Habitat modification. Urbanization modifies both the structure and functioning of natural habitats. It simultaneously alters physical and chemical characteristics, as well as species composition, and together, these can affect biogeochemical cycles nonadditively (Alberti 2008). Land cover conversion results in rapid loss of native habitat (Grimm et al. 2008) leading to extinctions, shifts in the relative abundance of species, and evolution (Alberti et al. 2017b). Altering the land surface also modifies microclimates and generates heat islands. Furthermore, an increase in impervious land area affects both geomorphological and hydrological processes, causing changes in water quality and dynamics of aquatic habitats. Human activities also alter the availability of nutrients and water, affecting population, community, and ecosystem dynamics (Alberti 2008).
Although ecologists have previously assumed that these impacts change predictably with distance from the urban core (Alberti et al. 2001), evidence shows that urbanizing regions are a mosaic of ecological gradients $(\mathrm{McD}$ onnell and Hahs 2008). Urban landscapes are best described by a set of patterns representing complex interactions between human and natural processes (Alberti 2005, Liu et al. 2007). Few studies have explored how alternative urban landscape patterns and infrastructure control the distribution of energy, materials, and organisms in urban ecosystems (Sukopp 1990, Alberti 2005, 2016, Kaye et al. 2006). Instead they typically relate ecological and evolutionary changes with simple aggregated measures of urbanization (e.g., human population density, percent of impervious surfaces). To understand how urbanization-driven habitat modification drives evolutionary processes it is essential to quantify the multiple axes of environmental variation that characterize urban environmental gradients across multiple spatiotemporal scales (Szulkin et al. 2020).

Driver 2: Connectivity. Cities change patterns of structural and functional connectivity by altering terrestrial and aquatic landscapes, isolating habitat patches, subpopulations, and species, and by transporting organisms (Bullock et al. 2018). Habitat fragmentation, which isolates populations from gene flow, is a major driver of both neutral and adaptive 


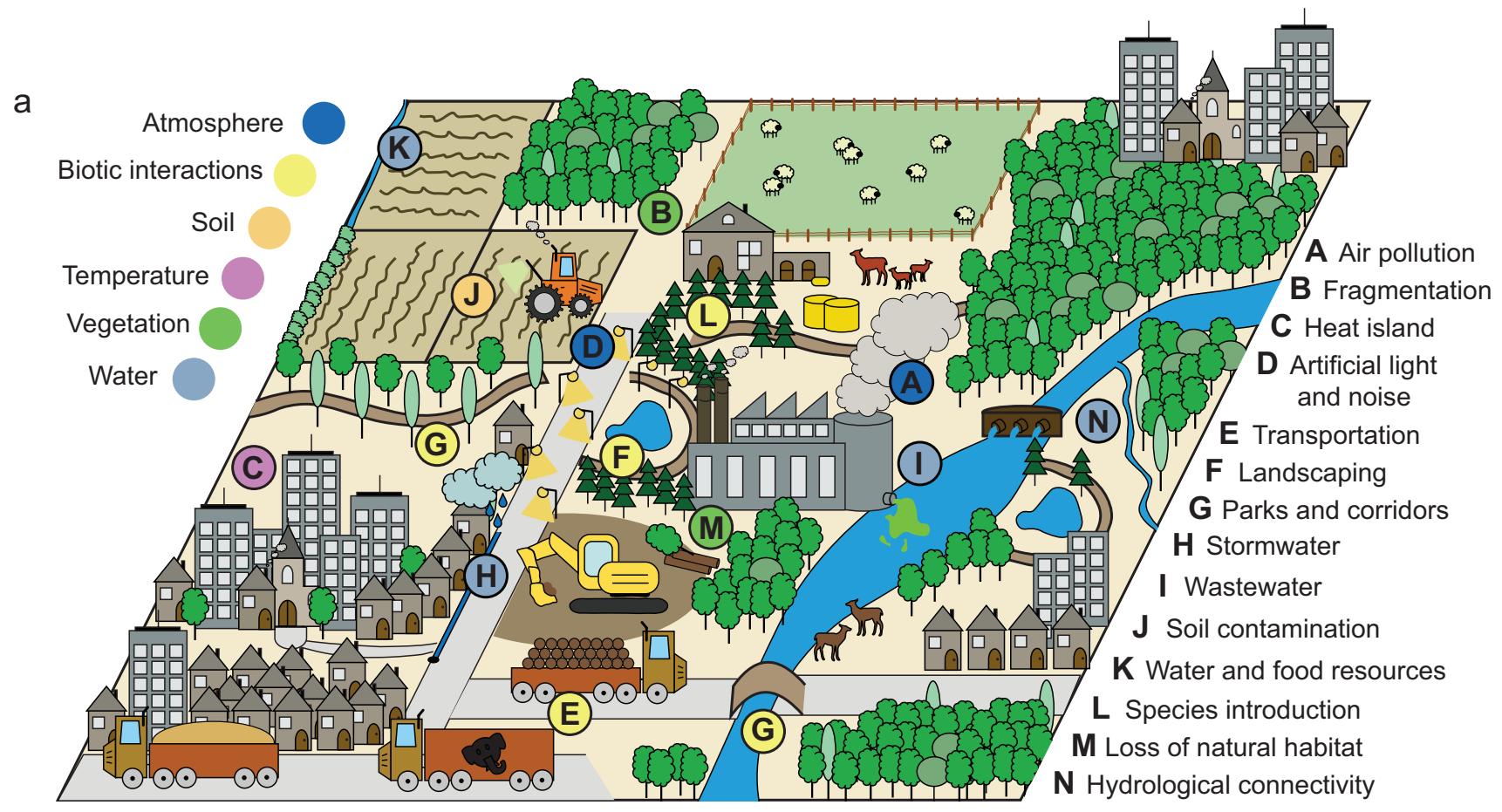

$\mathrm{b}$

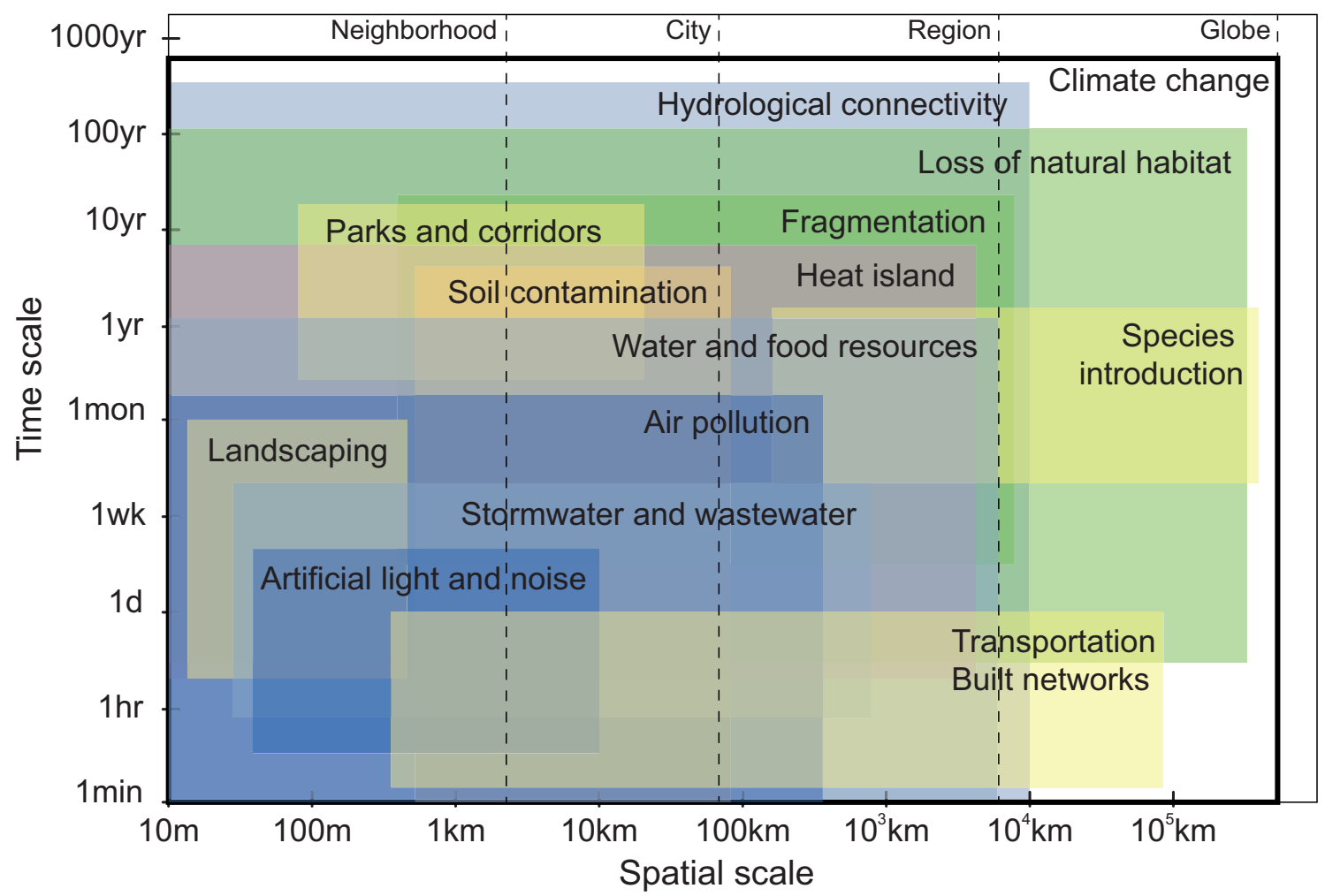

Figure 4. Agents and scales of urban eco-evolutionary change: Panel (a) shows the urbanization-driven selective pressures and direct ecological processes involved. Panel (b) identifies the spatiotemporal scales of ecological processes affected by the urban pressures (Modified from McDonnel and Hahs 2015).

evolutionary change. Isolation can prevent the influx of new genetic variation and increase inbreeding and neutral drift. When enough genetic variation exists in isolated habitats, reduced gene flow can also facilitate local adaptation by reducing the swamping of maladaptive gene flow. Natural habitat patches and their biological communities are often isolated from each other by the built environment. New barriers make dispersal difficult and can penalize less-mobile 
organisms or allow them to become more locally adapted (Rebele 1994).

Conversely, there is some evidence that urbanization can connect, intentionally or not, habitat patches, subpopulations, and species previously isolated from each other (Miles et al. 2019). Green infrastructure (e.g., green corridors)designed to provide habitat for wildlife and simultaneously mitigate storm water flows, reduce surface heat, cool the atmosphere, absorb atmospheric pollutants, and provide leisure opportunities for people-can allow for the movement of organisms and strongly influence habitat connectivity (Rudd et al. 2002, Bullock et al. 2018). Transportation infrastructure might, through traffic, act as an unintended dispersal vector for many organisms. These networks can allow range expansion and increase both dispersal rates and distances. Urbanization therefore profoundly rewires connectivity and differently affects species with alternate dispersal strategies, sometimes leading to evolutionary change in dispersal mechanisms (Cheptou et al. 2008). Through changes in species composition and altered food webs, rewired connectivity networks affect ecosystem function and feedback on trait evolution.

Driver 3: Spatial and temporal heterogeneity. Urban landscapes exhibit unique spatial and temporal heterogeneity (Cadenasso et al. 2007, 2013). Because the amount, form, and timing of urban development affect the mosaic of habitat patches and their ecological properties, we expect alternative urban development patterns to differently affect ecological and evolutionary dynamics (Alberti 2005). This heterogeneity would suggest greater niche differentiation and a relatively high species diversity in urbanizing regions. However, most studies report that habitat changes associated with urban land uses, along with other urban pressures, act as a filter for urban species composition (Piano et al. 2017, Merckx et al. 2018), with clear winners and losers, potentially driving the homogenization of ecological structures and functions across cities (Groffman et al. 2014). However, findings are not consistent across cities, and urban biodiversity might strongly be shaped by the regional species pool (Aronson et al. 2014). Urbanization pressures might differently affect the many dimensions of biodiversity (Pearse et al. 2018).

Urban spatial heterogeneity and its effect on community dynamics is not well understood partly because studies have tended to focus primarily on aggregated measures of urbanization (e.g., population density or impervious surface cover) and at biologically irrelevant spatial resolution (Szulkin et al. 2020; e.g., census blocks), and partly because we have insufficient knowledge on how this heterogeneity varies with scale (Band et al. 2005, Satgé et al. 2019). Recent observations show that urbanization tends to increase spatial heterogeneity on some scales and reduce it on others (Pickett et al. 2016). At the scale of meters or below, urbanization may reduce the heterogeneity of land cover, but at the landscape patch scale, urbanization may introduce new, highly heterogeneous biophysical conditions as the varied behaviors of landowners result in fragmented management patterns. Such trends may reverse at a larger scale because of consistent patterns of urban development and habitat fragmentation, which are likely to be influenced by cultural and historical legacy as well as climate (Szulkin et al. 2020).

Temporal heterogeneity in urban environments is altered by the type and timing of urban pressures associated with human activities. Physiological and reproductive cycles of many organisms of plants and animals are often triggered by climatic variation and resource availability (Cleland et al. 2007), which are both, in turn, altered by urbanization. Using three decades of high-resolution remote sensing observations, Li and colleagues (2017) found that that the phenology cycle (changes in vegetation greenness or senescence) in urban areas starts earlier and ends later than in rural areas resulting in a longer growing season. In addition to changing environmental conditions such as food and temperature, cities' artificial lights at night alter organisms' natural photoperiod (the daylight period of a 24-hour day), an important proximate cue that organisms use to time biological rhythms (Helm et al. 2013).

At some scales, temporal heterogeneity of urban areas tends to be reduced because of human behavior and built infrastructure (Walker et al. 2009). In warm, dry climates, irrigation evens out the otherwise widely varying primary productivity of native grassland or desert ecosystems. Dams modify riverine ecosystems, eliminating high-flow events and increasing low flows. Bird lovers provide seeds that can modulate food availability (Faeth et al. 2005). This buffering of environmental change, however, contrasts with disturbances that can occur over very short time scales. The temporal heterogeneity of human activities can result in higher variability of environmental pollution (e.g., night lights, atmospheric emissions, and noise) and physical structure (e.g., cleaning of urban ponds). In one example, real-time monitoring suggests significant effects of temporal heterogeneity of traffic patterns on the spatial concentrations of atmospheric pollutants (Liu et al. 2018).

Changes in spatial and temporal heterogeneity together with the reduction in habitat quality may therefore generate asymmetrical selective pressures and species responses. These asymmetries favor certain species and traits over others, changing biotic interactions and community composition, and could potentially result in ecological homogenization (Groffman et al. 2014).

Driver 4: Novel disturbances. Human activities can increase or decrease the magnitude, frequency, and intensity of natural disturbances (Rebele 1994), and can also introduce novel disturbances, defined in the present article as discrete events that disrupt system structure, which includes social, ecological, physical, and built components (Grimm et al. 2017), and that are unique to urban systems. For example, although building and construction regulations have dramatically reduced the risk of severe fire in cities and water 
flow regulation has decreased flow variability and "controlled" floods, changes in impervious cover have increased the intensity of floods. Also, the construction of new buildings and infrastructure can mean vegetation is permanently removed; surfaces are excavated, filled, and graded; and streams are buried (Elmore and Kaushal 2008) - all of which can disrupt habitat connectivity. Planting and maintaining ornamental vegetation introduces novel habitat and food resources, but also replaces native vegetation, eliminating habitat or food resources for many native species (Narango et al. 2018). The application of herbicides and pesticides and deliberate or inadvertent release of other pollutants into air, water, and soil cause mortality and persistent contamination. In many cases, continued management of these novel ecosystems (which could be viewed as a press disturbance) prevents the reestablishment of previously extant communities and sets the stage for novel biotic interactions (Collins et al. 2011). These novel environments lead to novel selection pressures and unexpected eco-evolutionary dynamics.

New spatial and temporal heterogeneity emerges from discrete disturbance events that modify the natural environment, creating a mosaic of built and highly managed natural components that form the urban ecosystem. Once established, these components are subject to disturbances such as fire, wind, pest outbreaks, and flood that may or may not transform their structure and identity. The type of disturbance that is most likely to transform them is another land conversion, such as the removal of a park to make way for a freeway, or the expansion of housing into previously undeveloped patches-with attendant losses or changes in species' habitats. However, the larger social-ecologicaltechnological system is likely to maintain its structure, function, and identity (i.e., to be resilient) except in the face of potentially catastrophic disturbances, such as hurricanes, sea-level rise, or major earthquakes. Once transformed to a new (urban) system state, eco-evolutionary dynamics will play out under the complex mechanisms of change that characterize urban social-ecological-technological systems (Grimm et al. 2017).

Driver 5: Biotic interactions. Urban development modifies species interactions, including competition, predation, parasitism, and symbiosis by introducing nonnative species, altering species behavior, and by changing species composition. In cities, frequent introductions of exotic species provide avenues for their colonization (Marzluff 2008) and establishment (McDonnell and Pickett 1993). This phenomenon is exacerbated as nonnative species take advantage of poorly integrated communities and patches typical of the disturbed sites in urban centers. Studies of genetic patterns and evolutionary consequences of urban colonization on native species include dark-eyed juncos (Junco hyemalis) in Southern California (Atwell et al. 2012), red fox (Vulpes vulpes) in Zurich (DeCandia et al. 2019a), and coyotes (Canis latrans) in New York City (DeCandia et al. 2019b, Henger et al. 2019). Marzluff (2008) developed a series of testable hypotheses about how urbanization affects colonization and extinction and therefore determines local diversity. In urban environments, diversity still emerges as the balance between extinction and colonization, but species invasion plays a prominent role.

Human activities in cities also alter food webs and trophic structure of biological communities (Faeth et al. 2005). A study of the urbanizing Sonoran Desert, conducted at the Central Arizona-Phoenix Long-Term Ecological Research site, revealed some surprising human-induced modifications of factors controlling trophic dynamics. Species composition was radically altered (e.g., generalist species increased) and resource subsidies from people increased and stabilized productivity (i.e., via modified water availability; Faeth et al. 2005). Birds as top predators were able to control abundance of arthropods. This suggests that urbanization may cause a shift from a system that is resource-based or bottom-up controlled-typical of the Sonoran Desert-to a combined bottom-up and top-down system.

Urbanization-driven changes in habitat quality interacting with rewired food webs also change eco-evolutionary feedbacks. Although research on eco-evolutionary dynamics has focused predominantly on individual species and at single trophic levels, evidence shows that intraspecific variation in multiple species can affect interactions between bottomup and top-down forces that shape communities (Rudman et al. 2015, De Meester et al. 2019). To fully understand urban evolutionary effects on ecosystems will require greater knowledge about how urban effects on genetic variation and genetic trait shifts can alter the strength of top-down control.

Urbanization also leads to an increase in human-wildlife interactions, with negative (e.g., physical attacks, disease transmission, property damage) and positive outcomes (e.g., ecosystem services, human well-being) that affect species traits and community composition (Soulsbury and White 2016). Humans serve as de facto apex predators in urban systems (Suraci et al. 2019), but at the same time have very strong effects on large carnivores that produce dampened top-down effects on urban animals (Oro et al. 2013). This results in overall increases in fearlessness and habituation directed toward people, which enables exploitation of novel niches and occasionally leads to increasing opportunities for conflict, both of which may serve as novel selection pressures in cities (Cox and Gaston 2018).

Anthropogenic food subsidies in cities also augment species habituation and risk-taking that can shape ecoevolutionary responses of urban populations (Oro et al. 2013, Martínez-Abraín et al. 2019). At the community level, food supplementation decouples predator-prey interactions that fundamentally alter food web dynamics (Rodewald et al. 2011, Fischer et al. 2012, Newsome et al. 2015). Wildlife-pathogen dynamics are also linked to increased resource provisioning by altering host exposure and tolerance to pathogens (Becker et al. 2015, Murray et al. 2019). Accordingly, direct and indirect human-animal interactions create ample opportunities for changed eco-evolutionary 
pathways in urban wildlife, as well as feedback to human health and well-being via zoonotic disease transmission and ecosystem services.

\section{Urban eco-evolutionary dynamics and feedbacks}

Evidence of urbanization-driven evolutionary change is rapidly expanding, but we lack a systematic mechanistic understanding of how urbanization affects evolutionary changes and their ecological feedbacks. Allele frequencies in a population may change because of mutation, genetic drift, gene flow, and natural selection. Research on eco-evolutionary dynamics has primarily focused on adaptive evolution, but neutral evolutionary processes may also influence feedbacks. Mutation is the original source of genetic variation. Mutations arise in response to air pollution; carcinogenic hydrocarbons, which cause increased mutation rates in birds (Yauk et al. 2000) and mammals (Somers et al. 2004); carcinogenic pollutants in water (Atlantic killifish; Whitehead et al. 2010); and toxins in soil (earthworms; Kille et al. 1999). Although there are a few documented examples of new mutations resulting from urban pollution (Alberti et al. 2017a), adaptation typically follows from existing allelic diversity or standing genetic variation (Barrett and Schluter 2008, Johnson and Munshi-South 2017).

Urbanization often causes drastic declines in population sizes, thereby exacerbating the effects of genetic drift-random changes in allele frequencies across generations. Genetic drift, which is more prominent in small, isolated populations, results in reduced genetic diversity within populations and increased differentiation among populations. Examples include populations of white-footed mice (Peromyscus leucopus; Munshi-South et al. 2016) and salamanders (MunshiSouth et al. 2013; Desmognathus fuscus) in New York City and foxes (Vulpes vulpes) in Zurich (DeCandia et al. 2019a). Other studies have shown that urbanization may increase regional genetic diversity by creating new habitats and ecological networks, thereby allowing for population growth and increased connectivity, which decrease genetic drift. Björklund and colleagues (2010) documented high genetic diversity in populations of the great tit in Barcelona. Miles and colleagues (2018) found high genetic diversity in western black widow spider populations across eleven US cities, as well as low genetic differentiation among populations.

Contrasting findings are also emerging from studies examining the effect of urbanization on dispersal and gene flow (Miles et al. 2018). Urban landscape fragmentation and the built structures are generally expected to impede gene flow, which reduces local genetic diversity and increases genetic divergence between urban and rural populations. Urban landscapes affect gene flow by rewiring connectivity networks through introducing artificial barriers that isolate populations and by establishing new corridors that may bring together previously isolated populations and species (Partecke 2013). Depending on the idiosyncratic effects of urbanization on dispersal for different species, urban landscape features can decrease or increase gene flow.
Urbanization mediates natural selection by influencing the fitness of individuals. Individuals with certain traits have higher survival and reproductive success rates than others and pass on these traits, when heritable, to their offspring. Phenotypic change exhibits a clear urban signal (Alberti et al. 2017a). However, we do not know how mechanisms of selection in the urban environment interact and what traits are most likely to evolve. Despite evidence of divergent phenotypic evolution in a wide diversity of traits (including life history, morphology, physiology, and behavior) between urban and rural environments, only a few studies link genetic mechanisms with phenotypic evolution. Perhaps the best known case of human-induced evolution is the increase in frequency of the darker color of the peppered moth (Biston betularia) in the 1800s, associated with industrial air pollution (Kettlewell 1958). San Diego populations of the dark-eyed junco (Junco hyemalis) have less white in their tail feathers as a result of sexual selection (Yeh and Price 2004). The Atlantic killifish (Fundulus heteroclitus) has rapidly adapted to high concentrations of PCB in four urban estuaries (Nacci et al. 2010).

Urbanization might shift the relative contribution of adaptive evolution versus species sorting to species persistence and biodiversity patterns. For example, urbanization might decrease colonization rates enough to prevent species from colonizing isolated urban environments. Free from disruptive gene flow and frequent colonizations, resident species might adapt to novel conditions and monopolize resources, and thereby reduce or prevent the colonization success of new species (De Meester et al. 2016). This scenario assumes enough genetic variation to mount an adaptive response, but genetic drift might reduce this potential especially in small populations. When urbanization enhances connectivity, species sorting is likely to be dominant over adaptation and monopolization, promoting the spatial insurance effect (Loreau et al. 2003) - whereby species can track their optimal environments by shifting their range. These patterns are not consistent across taxa and cities. An urban environment can reduce or increase colonization rates, genetic drift, and gene flow, changing the relative importance of species sorting and evolutionary dynamics depending on the characteristics of species and built environments.

Eco-evolutionary feedbacks resulting from urbanizationdriven evolutionary change may be amplified or modified by the divergent responses in ecologically relevant traits to complex urban signatures characterized by interactions among multiple environmental gradients (Alberti et al. 2017a) such as changes in microclimate, species interactions, and habitat fragmentation. Eco-evolutionary feedbacks are insufficiently studied in an urbanization context, but are likely very important. Urbanization has been associated with the evolution of ecologically relevant traits such as body size and dispersal ability within and among species (Johnson and Munshi-South 2017). Evidence of ecological responses to evolutionary trait changes in microbial (Fukami et al. 2007, Hiltunen et al. 2017), aquatic (Matthews et al. 2011, 
Pantel et al. 2015, Des Roches et al. 2018) and terrestrial (Fitzpatrick et al. 2015, terHorst and Zee 2016) ecosystems show potential feedback on key ecosystem functions that provide important contributions to people (e.g., primary productivity, nutrient cycling, pollution control, carbon sequestration, and community composition).

\section{Tackling emerging complexities}

Cities provide a unique opportunity to advance our understanding of urban eco-evolutionary dynamics. Cities' shared ecological features enable us to test hypotheses about the repeatability of evolution (Donihue and Lambert 2015, Santangelo et al. 2020) and to determine whether traits show convergence across different species or parallel changes across populations of the same species (Campbell-Staton et al. 2020). The heterogeneity and connectivity caused by variable patterns of urbanization within and among cities pose different challenges for different organisms and therefore provide opportunities to test both convergent and divergent evolution.

Disentangling the diversity of urban mechanisms and complex interactions that determine eco-evolutionary dynamics poses significant practical challenges. It may require common garden experiments (Brans et al. 2020 ) or reciprocal transplants of coevolved communities (Alexander et al. 2015), and such approaches may be possible only for certain species. Coupling landscape genomics (Manel and Holderegger 2013) with partition metrics (Govaert et al. 2016) can help determine the ecological and evolutionary contribution of different urban drivers to ecoevolutionary change across and within cities (Fenderson et al. 2020).

We propose five key aspects of complexity that need to be considered in future research, propose concrete approaches to tackle these complexities (table 1) and suggest an integrated approach using the evolving metacommunity framework. For example, we can begin to ask whether organisms are adapting to specific pressures (e.g., increased temperature) or to the cooccurrence of multiple pressures (e.g., temperature and pollution), how spatial interactions affect adaptation, whether there are detectable thresholds, and how their adaptation may be affected by cross-scale interactions (e.g., regional climate change and urban heat islands), and whether the cooccurrence of stressors limits or strengthens adaptation to individual stressors. Ideally, to explore generalities, this complexity should be unraveled for multiple organisms. The water flea Daphnia is perhaps one of the most documented examples of eco-evolutionary dynamics and provides an excellent model system to study urbanizing regions (box 2).

Landscape complexity. We propose that urban landscapes are emergent phenomena resulting from local interactions of human agency, built infrastructure, and biophysical factors. It is the cooccurrence of multiple and largely novel changes in habitat (habitat modification) and landscape (connectivity and heterogeneity) that sets the eco-evolutionary dynamics of urban ecosystems apart from natural and other anthropogenic systems. Urbanization gradients are multidimensional and have complex effects on biological assemblages and ecosystem processes across a range of temporal and spatial scales (Alberti et al. 2003, Cadenasso et al. 2006).

Future studies will need to treat urban landscapes as spatially heterogeneous patch mosaics, characterized by multidimensional gradients structured hierarchically. Drawing on gradient (Whittaker 1967), patch (Levin and Paine 1974), network (O'Neill et al. 1986), and hierarchy theories (Wu and Loucks 1995), we can quantify different aspects of urban habitat and landscape complexity that we expect to affect evolutionary and ecological processes using selected habitat and landscape metrics that have been shown to capture the spatiotemporal signatures of urbanization (table 2; Liu et al. 2016b). These metrics offer a concrete approach to link urban landscape complexity to ecosystem function (Levin et al. 1998) and explore how alternative development patterns across and within cities produce distinct signatures of eco-evolutionary change. Using landscape genomics (Manel and Holderegger 2013) and spatially modified partition metrics (Govaert et al. 2016), we can further determine the ecological and evolutionary contributions and assess what landscape properties explain the observed variation.

Urban discontinuities. Urbanizing landscapes represent spatial and temporal discontinuities (Holling 1992, Allen and Holling 2002) in the relationships between human and natural systems across a continuum of anthropogenic disturbance (figure 2; Alberti 2008). These discontinuities can be either caused by abrupt changes in selection pressures in space and time or by nonlinear responses to a gradient in anthropogenic disturbances (Scheffer et al. 2001). The cooccurrence of multiple disturbances can lead to synergistic interactions and multiplicative effects. In addition, the ecological and evolutionary responses to the stress gradients can influence these discontinuities (Dakos et al. 2018). Tipping points represent system transitions between alternate states that occur when a controlling variable in a system reaches a threshold. Subtle environmental change then can set the stage for large, sudden, surprising, and sometimes irreversible changes in ecosystems. Regime shifts depend not only on the perturbation but also on system resilience (Holling 1973, Scheffer et al. 2001). Tipping points can be influenced by eco-evolutionary feedbacks-for instance, when reduced genetic diversity in urbanized regions lowers the resilience of populations to deal with certain environmental fluctuations (Dakos et al. 2019). Even if environmental fluctuations would remain similar across the urbanization gradient, it might then still be that the population crashes at a given level of urbanization.

Regime shifts have been observed in many ecological and social systems and have been described in coupled socioecological systems (Scheffer et al. 2001). In one example, 


\section{Table 1. Emerging complexities, hypotheses, principles, and approaches.}

$\begin{array}{llll}\text { Complexities Concepts Hypotheses } & \begin{array}{l}\text { Principles for urban Research approaches/methods } \\ \text { eco-evolutionary } \\ \text { research }\end{array}\end{array}$

\begin{tabular}{ll}
\hline Landscape & Urban landscapes are \\
complexity & emergent phenomena \\
& resulting from local \\
& interactions of human \\
& agency, built infrastructure, \\
& and biophysical factors. \\
& Examples are urban sprawl, \\
& habitat connectivity, and \\
& heterogeneity resulting from \\
& local-scale interactions \\
& among variables such as \\
& topography, land cover, \\
& transportation infrastructure, \\
& real estate markets, and \\
& social preferences.
\end{tabular}

Urban

discontinuity

Socio-ecological heterogeneity

Cross scale interactions
Urbanizing landscapes represent spatial and temporal discontinuities in the relationships between human and natural systems through abrupt changes in selection pressures, or by non-linear responses to anthropogenic disturbances. E.g. reduction in nitrogen retention capacity caused by land cover change can constrain responses to increases in nutrient loading, shifting urban lakes to an eutrophic state. Adaptation of zooplankton to cyanobacteria can affect at which disturbance level a shallow lake shifts to a turbid state.

Urbanizing landscapes exhibit unique heterogeneity due to natural and engineered landscape elements, socio-economic and cultural factors, and the behaviors of individuals and institutions.

Cities affect eco-evolutionary change well beyond the city boundaries and interact with other sources of evolutionary change (e.g., climate change).

Interactions between drivers occur across multiple spatiotemporal scales; including global sea level rise and geologic formation, global trade and regulations, local-scale microclimates, point source pollution or microbial activity, and community practices and businesses.

Diverse urban patterns (i.e., urban

form, land-use distribution, and connectivity) generate differential effects on eco-evolutionary dynamics.

We hypothesize that alternative urbanization patterns have variable impacts on the sources of ecological and genetic variance that are expressed at fine spatial and temporal scales.

Urban discontinuities emerge from the interaction of multiple drivers (e.g. habitat modification and change in connectivity and heterogeneity) amplified or dampened by feedback loops that can lead to tipping points, regime shifts, and feedback structures. Urban discontinuities can be detected in ecoevolutionary change.

Social heterogeneity Scale is a might amplify dynamics of ecological heterogeneity in urban systems, while evolution might more often dampen it. Environmental inequalities such as uneven distribution of parks, tree canopy cover, and vacant lots create patterns of eco-evolutionary dynamics.

Increasing crossscale interactions between human and natural systems, from preurban to more humandominated systems, alters the dynamic relationship between species sorting and adaptation that might shift the balance between the probability of evolutionary rescue versus extinction. scales.

Creating a
Urban landscapes exhibit emergent propertiesproperties that cannot be understood by studying the properties of their constituent parts. The nature and structure of the relationships between system components and selective pressures have to be considered explicitly in

designing urban ecoevolutionary studies.

Ecological structures and processes occur at specific spatiotemporal scales, and interactions that occur across multiple scales mediate scale-specific (e.g., individual, community, local, or regional) responses to disturbance. Urban ecosystems represent a discontinuity in eco-evolutionary dynamics.

Identify social and ecological processes necessary to predict urban ecosystem-level properties.

Use landscape metrics to characterize habitat and landscape complexity.

Couple landscape genetics and metrics to estimate gene flow across landscapes.

Genome scans combined with genetic samples across urban landscapes to identify molecular markers indicating adaptive genetic variation (Manel and Holderegger 2013).

Use spatial modified partition metrics (Govaert et al. 2016) with landscape metrics (Liu et al. 2016b) to determine ecoevolutionary contributions of urban landscape properties to eco-evolutionary change across and within cities.

Identify feedbacks across different spatial and temporal scales.

Explore complex causalities that emerge from multiple interacting factors, starting points and pathways (Preiser et al. 2018)

Detect thresholds and early-warning signals of possible regime shifts (Dakos et al. 2018). Anticipate alternative future outcomes by developing scenarios (Preiser et al. 2018) Assess ecosystem states across cities (e.g., clear versus turbid ponds) in relationship to variable urban landscapes to explain drivers of urban discontinuities (Dakos et al. 2018)

critical factor in understanding the interactions between human and natural sources of evolutionary change since spatial and temporal heterogeneity may affect the outcome of changes in driving forces only at certain

predictive, integrated understanding of urban ecoevolutionary dynamic requires tackling the complex interactions of human and natural processes operating at different space and time scales.

Integrate socio-economic variables in sampling design using multiple socioeconomic and ecological data sources combining grid, vector, and network data to develop multi-dimensional transects.

Extend methods that quantify eco-evolutionary contributions (Govaert et al. 2016) to include socio-cultural dynamics.

Identify hypothesized cross-scale interactions and feedbacks among drivers and focal responses (Soranno et al. 2014); measure eco-evolutionary responses at multiple scales and test for significant effects of variables' interactions at each scale (Peters et al. 2007); integrate data from observations, long-term experiments, and theoretical models to examine ecosystem processes at multiple spatiotemporal scale (Peters et al. 2018); sensitivity analysis of scaling relationships to urban structure and heterogeneity using simulation methods (e.g. Markov Chain Monte Carlo) (Wei et al. 2017). 


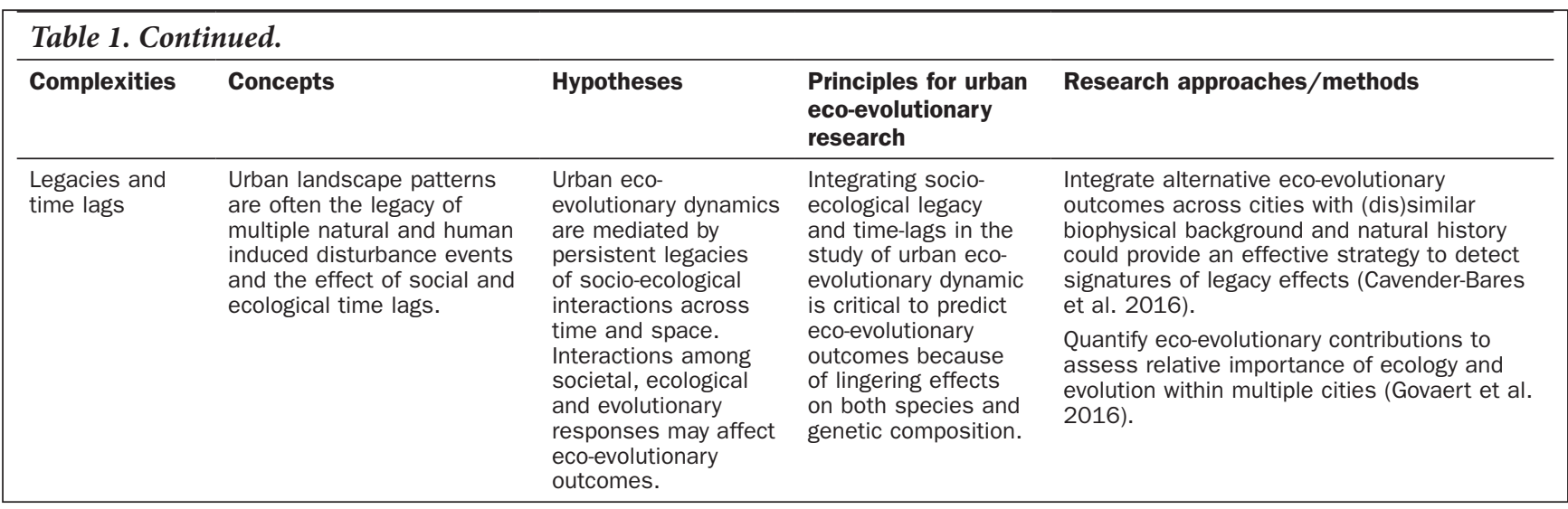

reduction in nitrogen retention capacity caused by longterm land-cover change associated with urbanization can constrain the responses to rapid increases in nutrient loading, generating a shift in a lake ecosystem from a clear to a turbid, algae-dominated state (Wagener 2003). This regime shift can affect evolutionary dynamics (Alexander et al. 2017) and drive eco-evolutionary feedbacks.

Dakos and colleagues (2019) show how trait change and trait variation can influence the probability and timing (delaying or anticipating) of a tipping point between two ecological states (figure 2). For example, adaptation of zooplankton to cyanobacteria or evolution of nutrient uptake in phytoplankton (Faassen et al. 2015) can affect the disturbance level at which a shallow lake shifts from a clear state to a turbid state. High trait variation can provide resilience to populations in the face of environmental change, whereas low trait variation can enhance the risk of regime shift. Urbanization-driven trait change can also affect the pathway to recovery to the previous state and its hysteresis-the time lag of the threshold in the environmental variable for the system to recover (Dakos et al. 2019).

Overall, we predict that the likelihood of nonlinear responses is high in urban systems, because the discontinuities may involve responses to environmental and social changes and their interactions. Multiple stressors in the urban environment can drastically change the offset point of a system shift. For example, in urban ponds the ability of zooplankton to adapt to cyanobacteria can be influenced by the ability of zooplankton to simultaneously adapt to higher temperature (e.g., heat islands) and the presence of other contaminants (e.g., pesticides), determining the disturbance level at which a pond will shift from a clear state to a turbid state. Several strategies can be applied to test this hypothesis, including assessing how a stressor changes a threshold level of a controlling variable, identifying feedbacks across different spatial and temporal scales, detecting thresholds and early-warning signals of possible regime shifts, exploring complex causalities with different starting points and pathways, and anticipating alternative future outcomes by developing scenarios (Preiser et al. 2018, Dakos et al. 2019).
Socio-ecological heterogeneity. Urbanizing landscapes exhibit unique heterogeneity because of a combination of natural and engineered landscape elements and because of the socio-cultural characteristics and behaviors of individuals and institutions (Machlis et al. 1997). Heterogeneity in urban ecosystems is therefore driven simultaneously by natural and human agents operating across the landscape (Alberti 2008). Diverse human agents (e.g., income groups, household sizes, business sectors) have different opportunities, preferences, and behaviors that affect the use of land, spatial distribution of activities, and the demand for and supply of resources. Development decisions (e.g., housing and infrastructure), management choices (e.g., yard management), and individual preferences (e.g., residential location choices) alter landforms and drainage networks, and enhance the heterogeneity of nutrients, material, and water cycling (Pickett et al. 1997). Although empirical studies of the effect of urban heterogeneity are still limited, initial findings highlight the complex interactions and divergent outcomes resulting from multiple sources of urban heterogeneity.

One of the best examples of an emergent urban landscape pattern caused by socio-ecological heterogeneity is urban tree canopy cover. Trees are unevenly distributed throughout the city because of both natural (e.g., microclimate, soil nutrients) and anthropogenic forces (e.g., income, unequal stewardship) that establish an urban habitat mosaic with salient fitness consequences for other organisms at higher trophic levels (Zipperer et al. 2011). For instance, urban trees are concentrated at greater densities in older, high-income neighborhoods relative to others (Clarke et al. 2013, Schwarz et al. 2015, Fan et al. 2019), which subsequently affects the distribution and intensity of urban heat islands and water quality throughout a city (Jenerette et al. 2011, Huang and Cadenasso 2016, Wang et al. 2019).

The hypothesis that species diversity tends to increase with neighborhood income suggests that socio-economic inequalities influence the suitability of specific habitats as corridors or stepping stones, shaping animal movement, genetic connectivity, and biodiversity (Leong et al. 2018) and can therefore affect eco-evolutionary dynamics. 


\section{Box 2. Daphnia: A model system for studying urban eco-evolutionary dynamics.}

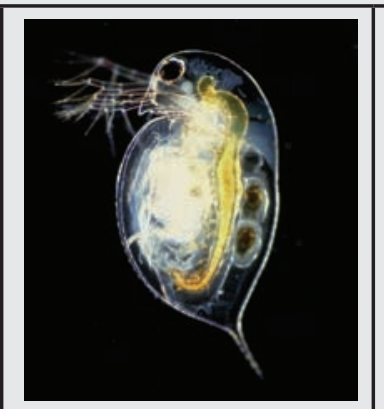

One of the best documented examples of a human-driven eco-evolutionary change is from the water flea Daphnia, a common zooplankton genus that plays an important role in the functioning of pelagic freshwater food webs (Miner et al. 2012). The different species of Daphnia, which are found in urban lakes and ponds, are excellent study systems for studying urban eco-evolutionary dynamics, as is illustrated in the following examples. Photograph: Paul Hebert.

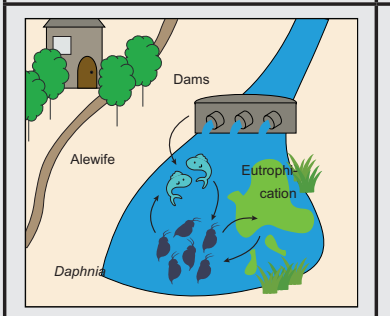

Alewife are anadromous fish that became landlocked in lakes following the construction of Colonial Era dams. Differences in the population growth rates of Daphnia ambigua that evolved to coexist with anadromous versus landlocked alewife populations alter consumer-resource dynamics and ecosystem function (Palkovacs et al. 2008, Walsh et al. 2012).

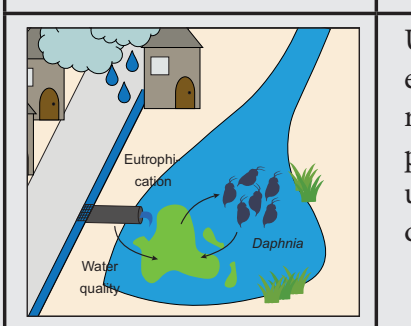

Urban eutrophication causes cyanobacteria blooms (made worse by warming), which drive rapid evolution of Daphnia pulex. Adapted D. pulex can tolerate cyanotoxins produced by cyanobacteria and therefore provide an ecological function (top-down control of phytoplankton) that is not provided by the maladapted $D$. pulex. Therefore, there exists an eco-evolutionary feedback from urbanization (eutrophication) to D. pulex evolution to ecological function (improvement of water quality for human use; Hairston et al. 2001).

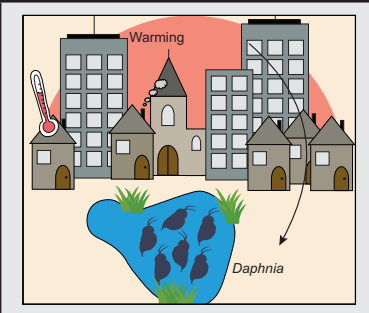

Daphnia magna in urbanized and warmer habitats rapidly evolve heat tolerance, and other changes in life history traits, and physiological responses (Brans et al. 2017b). Adaptation to urban heat islands might interact with population's response to higher temperature because of climate change (Brans et al. 2017a). Although for Daphnia magna, the largest cladoceran and most efficient grazer, urban populations evolve smaller body sizes in response to warming, their persistence in the system via thermal adaptation (reduced body size, increased heat tolerance) could still mitigate top-down control and ecological functioning rather than be replaced by a smaller species.

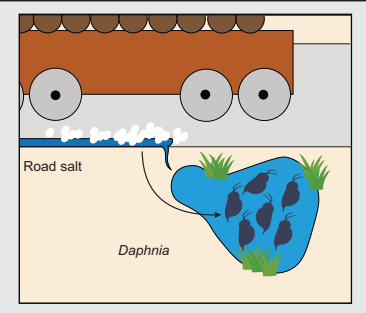

Daphnia galatea have shown rapid adaptation to road salt. The evolved tolerance of $D$. galatea to road salt could mitigate trophic cascades due to the impact of lake salinization that would otherwise lead to elevated phytoplankton levels (Coldsnow et al. 2016).

However, economic inequality and unequal distribution of biodiversity do not always converge (Kuras et al. 2020). The exact mechanism that links socio-economic variables to differences in biodiversity is not known. The legacy effect of historical societal processes observed in cities (Grove et al. 2018, Roman et al. 2018) highlights the need to uncover the social determinants of urban eco-evolutionary processes (Des Roches et al. 2020), and studies focusing on these associations need to take into account the high temporal and spatial heterogeneity of urban centers. This can be achieved by integrating socio-economic and socio-cultural variables in sampling design using multiple socio-economic and ecological data sources to develop multidimensional transects to compare eco-evolutionary change within and across cities.

Cross-scale interactions. Creating a predictive, integrated understanding of urban eco-evolutionary dynamic requires tackling the complex interactions of human and natural processes operating at different spatial and temporal scales. 
Table 2. Urban complexity metrics.

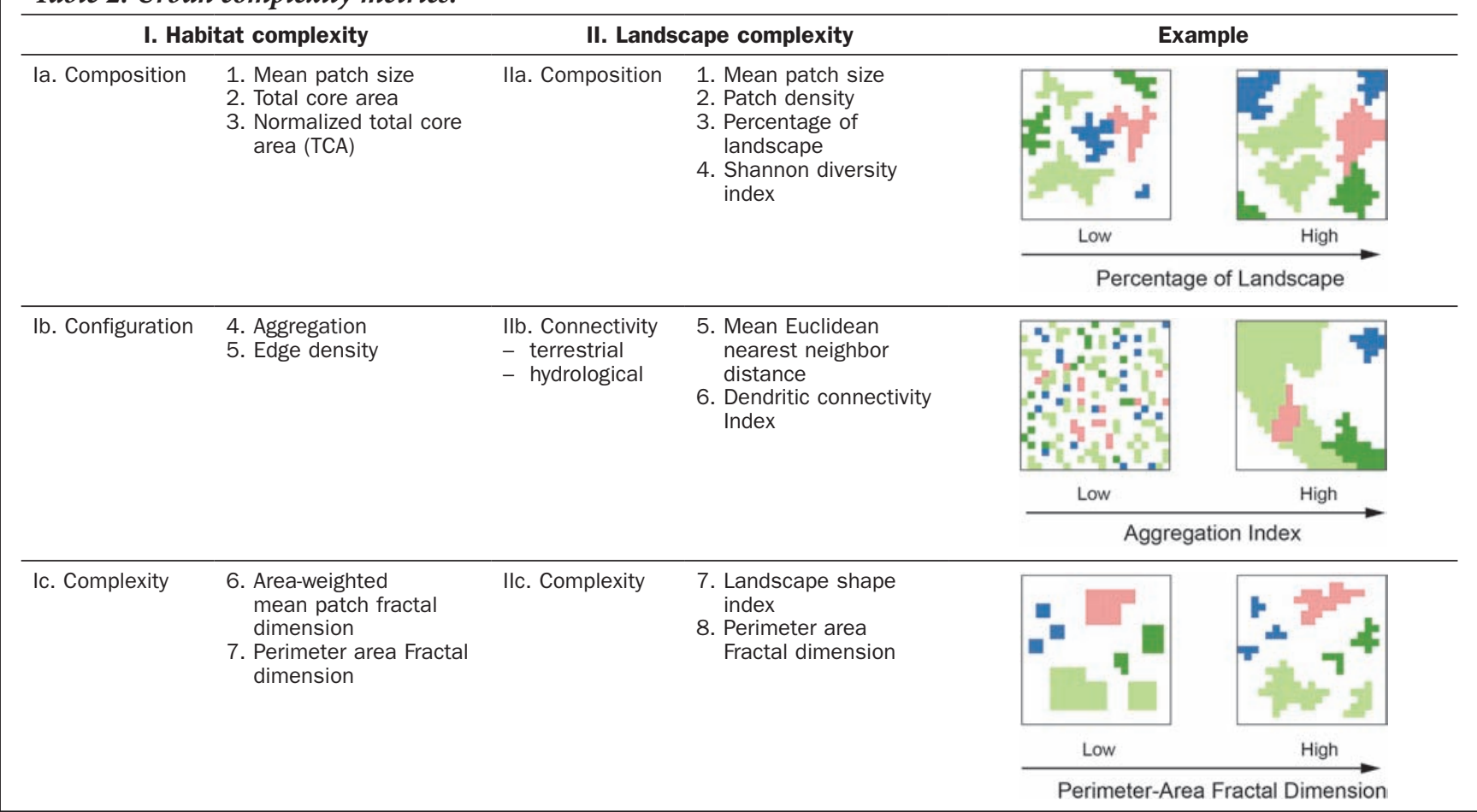

Although we have been aware of the existence of spatial and temporal asymmetries between nature and society for quite some time, we do not yet have a theoretical framework for studying the dynamics they create.

Complex interactions resulting from changes in habitat and biotic interactions might produce new trophic dynamics across the urban landscape (Faeth et al. 2005). These would result in profound changes in the structure and functioning of communities and ecosystems that need more targeted research. This also needs to be considered at the appropriate spatial scale, because urbanization-induced ecological, evolutionary, and eco-evolutionary changes might be scale dependent. There is a need for systematic studies on how urbanization-mediated ecological and evolutionary responses interact differently among areas within cities, among cities, and beyond cities. Cities differ strongly in their urbanization dynamics. Comparative studies can link these dynamics to eco-evolutionary feedbacks. In addition, there is an important need for studies that quantify how urbanization affects community and ecosystem structure and functioning in their surroundings and globally.

Cities affect eco-evolutionary change well beyond the city boundaries and interact with other sources of evolutionary change. Scale is a critical factor in understanding the interactions between human and natural sources of evolutionary change. City functions depend on highly interconnected infrastructures and on flows of material, energy, and information from both adjacent regions (e.g., via hydroelectric dams) and distant ones (e.g., via trade and telecommunication; Alberti et al. 2018). Distant coupled human-nature interactions are more prevalent and occur at higher speeds (Liu et al. 2016a). Such complex interactions in telecoupled systems make it particularly challenging to disentangle urban versus rural anthropogenic and natural drivers and to understand the potential ecoevolutionary implications of cross-scale interactions and the associated feedbacks.

Strategies to tackle cross-scale interaction may include identifying hypothesized cross-scale interactions and feedbacks among regional and local drivers and between them and focal responses (Soranno et al. 2014); measuring ecoevolutionary responses at multiple scales and testing for significant effects of variables' interactions at each scale (Peters et al. 2007); integrating data from multiple lines of evidence including observations, long-term experiments, and theoretical models to examine ecosystem processes at multiple spatiotemporal scales (Peters et al. 2018); and conducting sensitivity analysis of scaling relationships to urban structure and heterogeneity using simulation methods (e.g., Markov Chain Monte Carlo) for a set of socio-ecological indicators for which we have disaggregated data (Wei et al. 2017).

Legacies and time lags. Theoretical models in biology predict that species and genotypes are distributed across heterogeneous environments according to their local optima, which vary over fitness landscapes (Norberg et al. 2012). However, historical contingency can also play an important role in community assembly (Fukami 2015, De Meester et al. 2016). Both ecologists and evolutionary biologists recognize that the order and timing of species arrival during community 
Contemporary evolution. Evolution of species' traits observed in contemporary time (i.e., less than a few hundred generations).

Eco-evolutionary dynamics. Reciprocal interactions between ecological and evolutionary dynamics.

Ecosystem. An ecological unit that includes all of the organisms in a given area interacting with the physical environment. The flow of energy and material leads to trophic structure and material cycles.

Ecosystem function. Processes that control the flux of energy, organic matter, or nutrients in an ecosystem, including the flux of biomass associated with trophic interactions.

Evolutionary change. Changes in allele frequencies within a single population due to natural selection, genetic drift, mutations and gene flow.

Evolutionary rescue. Demographic recovery preventing extinction due to genetic adaptation within a population facing environmental stress.

Green infrastructure. A planned network of natural and seminatural areas with other environmental features, designed to protect biodiversity and deliver a wide range of ecosystem functions.

Habitat. An ecological or environmental area characterized by both physical and biological features, which is inhabited by a particular species or community of organisms.

Metacommunity. A set of interacting communities that are linked by the dispersal of multiple, potentially interacting species.

Monopolization. An evolution-mediated priority effect whereby the arrival order of species and their evolution influences community dynamics and structure.

Niche construction. The process whereby organisms actively modify their own and each other's habitat so that they influence their evolution.

Press disturbance. Environmental disturbance that may arise sharply and then reach a constant level that is maintained.

Priority effect. The arrival order of species influences community dynamics and structure.

Regime shift. Large, abrupt change in the structure and function of a system causing a shift between two alternate stable states following discontinuous nonlinear dynamics.

Spatial insurance. Biodiversity provides spatial insurance for ecosystem functioning by spatial exchanges among local systems in heterogeneous landscapes.

Species sorting. Community assembly mechanism in which species composition in a given locality or patch is determined by their responses to the local environment (i.e., their niche), including the presence of other species in the locality or patch. The resulting match between species occurrences and abundances with the environment is also fueled by dispersal allowing species to colonize patches with their preferred habitat.

Urban ecosystems. Coupled human-natural systems in which people are the dominant agents and characterized by high human population densities.

Urban. Areas where people live at high densities and in high numbers, or where the built infrastructure covers a large portion of the land surface. The US Census defines urban agglomerations as having 2500 or more inhabitants, generally with population densities of 1000 or more persons per square mile.

assembly can affect species abundance and the structure and function of the resulting communities. The arrival order of species or genotypes in a specific habitat patch may influence the community and genetic structure and their dynamics (Fukami 2015). This priority effect influences community assembly and diversity through both ecological and evolutionary mechanisms and mediates the emergence of ecological patterns under environmental change (Urban and De Meester 2009, De Meester et al. 2019). Time and the fate of local versus immigrant species and genotypes in an urbanizing landscape are expected to be important, but virtually no studies have tackled this in a systematic way. We can gain some insights on such dynamics from work examining climate change. Norberg and colleagues (2012) show how under climate change the outcome depends on rates of evolution, dispersal, and environmental change, as well as the adaptive and dispersal abilities of different species and genotypes.

Understanding the legacy effects arising from evolutionary priority effects and biogeographic history on community 
assembly and diversity is important for predicting the responses of species to urbanization (Cavender-Bares et al. 2016). Differences in eco-evolutionary responses among urban regions may reflect legacies from preurban land uses and associated agricultural and forest practices (Ziter et al. 2017). Patterns of biodiversity in urbanizing regions may also reflect the legacy of past human settlements and relatively recent infrastructure constructed more than 100 years ago (Hahs et al. 2009). The time lag-the period of time between a disturbance and its effect-might play an important role in urbanizing landscapes. For example, wetland biodiversity response is better explained by historical than current densities of road construction (Findlay and Bourdages 2000). Lagged eco-evolutionary responses to urban environments interact with the cumulative nature of legacy effects of the historical development of cities to shape biodiversity responses to urbanization. In addition, both the speed of change in urban environments and the variability across time, are critical to understanding whether species will evolve, disperse, or go extinct. In many ways, urbanization might be one of the fastest environmental changes and therefore might swamp the adaptive responses of some species, replacing them with generalist, short generation, or invasive ones.

How can we disentangle the impact of regional biogeographic processes and historical contingencies from contemporary urbanization-driven evolutionary change on community assembly and diversity? Developing cross-comparative studies of cities where alternative eco-evolutionary outcomes have been observed against similar biophysical background and integrating evolutionary history could provide effective strategies to detect signature of legacy effects and explain urbanization-driven eco-evolutionary dynamic (Cavender-Bares et al. 2016).

\section{Evolving urban metacommunities}

Despite an increased understanding that the variation among and within species, including evolutionary dynamics, can profoundly affect community dynamics and shape biodiversity (Bolnick et al. 2011), these processes have been primarily studied in isolation. The multivariate and dynamic gradients typical of urbanizing landscapes can lead to both species sorting and evolutionary trait change. This complexity offers plenty of opportunities for eco-evolutionary interactions in a spatially explicit context. Recent research, primarily in the context of climate change, has explored how genetic variance and dispersal together affect eco-evolutionary dynamics and biodiversity along a dynamically changing gradient (Norberg et al. 2012). Dispersal can prevent extinction by allowing species to move to areas with suitable environmental conditions (spatial insurance; Loreau et al. 2003), whereas genetic adaptation can allow populations to persist in a changing environment (evolutionary rescue; Loreau et al. 2003, Bell 2017). Both processes interact, leading to dynamics that are profoundly different than one would expect in the absence of evolution or in the absence of other species (Urban et al. 2012, De Meester et al. 2016).
The evolving metacommunity concept provides a powerful framework to address the potential for eco-evolutionary dynamics in urbanizing landscapes (Brans et al. 2020), because it explicitly addresses multiple species (De Meester et al. 2019) and spatial scales, and aims at integrating community and metacommunity dynamics (Leibold et al. 2004) with intraspecific trait variation and evolutionary change in spatially explicit landscapes (Urban et al. 2008). Urbanizing landscapes are ideally suited for this framework because of the importance of spatial structure within cities, the patch-like nature of urban centers in the landscape, the striking difference in size and spatial structure of environmental gradients among cities, and the explicit spatial context of urban sprawl. The evolving metacommunity context allows us to capture interactions between ecological and evolutionary dynamics in the context of urbanization, and to also consider cross-scale interactions-for instance, when the metacommunity dynamics in urbanizing centers influence community assembly in the rural matrix by changing the pool of dispersing species or genotypes. So far, very few studies have tried to tackle both community and evolutionary dynamics along urbanization gradients (Brans et al. 2017a). This is in part because of the challenging nature of integrating space, ecological and evolutionary dynamics, and in part because most studies documenting evolutionary responses to urbanization are rather recent (Johnson and Munshi-South 2017). The approaches that can help move the field forward are very diverse and include the analysis of inter- and intraspecific trait variation along urbanization gradients and among cities (Brans et al. 2017a), the application of eco-evolutionary partitioning tools, transplant experiments (Merilä and Hendry 2014), manipulating community identity or genetic identity along urbanization gradients, comparative surveys on evolving metacommunity structure across cities that differ in history or size, and monitoring both community and evolutionary dynamics in areas of urban sprawl (Brans et al. 2020).

The evolving metacommunity framework can also provide insights on how urbanization might influence responses to other aspects of global change, such as climate warming or exotic species, because the spatial dimension of the spread of exotic species and the fact that their evolution can affect the success of invaders are characteristics captured by the evolving metacommunity framework (Faillace and Morin 2016).

\section{Rethinking urban sustainability with an eco- evolutionary perspective}

Evidence of accelerated evolutionary change associated with urbanization highlights the importance of rethinking urban sustainability strategies. However, our current limited understanding of eco-evolutionary feedbacks and the lack of agreement on the overall ecological and evolutionary prevalence and magnitude of these changes pose significant challenges to attempts to translate an eco-evolutionary perspective into sustainability strategies. 
A novel understanding of urban eco-evolutionary dynamics that fully accounts for cities' complexity and heterogeneity will constitute a key step toward bridging the gap between the science of urban eco-evolutionary dynamics and sustainability practices. For example, different designs of urban infrastructure (e.g., stormwater or flood control) have different impacts on pollution loading and hydrological connectivity, and different management strategies have different effects on evolutionary mechanisms and ecosystem feedback (Post et al. 2008, Walsh et al. 2012). Green infrastructure (e.g., street trees, bioswale, green roofs, and detention ponds) can facilitate adaptation and help maintain genetic diversity (Lundholm 2015, Beninde et al. 2018, Ksiazek-Mikenas et al. 2019). Alternative conservation and restoration strategies can reverse or buffer eco-evolutionary feedbacks (Kinnison and Hairston 2007, Carroll 2011). An accurate representation of the variability of urban mechanisms associated with varied configurations of the urban habitat is crucial to determining the importance and sensitivity of different factors to policy scenarios.

The uncertainty of future eco-evolutionary feedbacks highlights the importance of maintaining both ecological and evolutionary diversity in a rapidly changing world. Identifying early warning indicators might be critical to anticipate potential consequences and implement mitigation strategies to promote ecosystem health in urban environments. Furthermore, uncertainty in species' adaptability highlights the importance of conserving evolutionary potential - the capacity of a population to evolve in response to environmental change. Genetic diversity, together with dispersal, may shape the eco-evolutionary effects of environmental change. For example, although recent models of evolutionary response to climate change disagree on whether or not dispersal rates in evolving species assemblages can preserve biodiversity under environmental change, most models find that high genetic diversity minimizes extinction risk (Thompson and Fronhofer 2019).

Diverse strategies have been proposed to facilitate adaptation and maintain or enhance genetic variation with respect to fitness and historic gene flow, including assisted migration and translocation of individuals likely to be more adapted to new environments (Smith et al. 2014). Maintaining ecological diversity, particularly in the form of antagonistic interactions (e.g., predation, herbivory, and parasitism), also promotes resilience within species networks (Toju et al. 2017). For example, high levels of predation, parasitism, and competition are characteristics of healthy ecosystems. Therefore, the persistence of antagonisms can help sustain eco-evolutionary feedbacks under perturbations in urban habitats. To succeed, urban biodiversity conservation strategies must account for evolutionary processes in defining management targets (Lambert and Donihue 2020).

Urbanization alters the distribution of genetic diversity through strong selection, changes in population size, and by altering gene flow. By reducing species diversity, urbanization can increase the potential for monopolization effects
(De Meester et al. 2016). However, lower genetic diversity may reduce the capacity of local populations to evolve and therefore may limit the degree to which monopolization occurs. Current findings show that urbanization can both reduce and increase genetic drift and gene flow, differently influencing genetic diversity and changing the dynamics set in place by global environmental change (Miles et al. 2019). Identifying the outcome of these dynamics across cities and organisms' groups is an important research question. Can alternative patterns of urbanization explain these alternative trajectories? What general properties of urban ecosystems can facilitate adaptation and maintain evolutionary potential? Answering these questions requires characterizing the complexity of urban eco-evolutionary dynamics to generate the knowledge that can inform the development of new principles for urban design and planning and a new urban sustainability paradigm.

\section{Conclusions}

Urbanization is altering biodiversity by directly and indirectly changing eco-evolutionary dynamics. Changes associated with urbanization alter interactions and feedbacks between ecological and evolutionary processes that can shift the balance between the probability of evolutionary rescue and extinction, affecting long-term evolutionary processes and ecosystem dynamics. But so far, little is known about how patterns of urbanization shape eco-evolutionary outcomes at the scale of single cities, across urban centers in an urbanizing landscape matrix, and even on a planetary scale.

We propose that emergent patterns of urbanization alter eco-evolutionary dynamics in ways that can generate complex feedbacks and unexpected outcomes. Cities affect ecological and evolutionary dynamics and their interactions through habitat modification, changes in connectivity and heterogeneity, novel disturbances, and altered biotic interactions. Different patterns of urbanization can produce different landscape signatures influencing ecological and evolutionary processes. These landscape signatures can result in variable interactions between dispersal, local genetic adaptation and species sorting that might reduce or reinforce the links between environments and species composition. We contend that accurately characterizing the complexity of emergent patterns of urbanization is an essential element to advance our understanding of ecoevolutionary dynamics and feedbacks in an urbanizing world and suggest that adopting an evolving urban metacommunity perspective can inform a new urban sustainability paradigm.

\section{Acknowledgments}

This overview article has benefited from collaborations of the National Science Foundation Research Coordination Network (RCN): Eco-Evolutionary Dynamics in an Urban Planet: Underlying Mechanisms and Ecosystem Feedbacks (grant no. DEB 1840663) and from discussions among and input from the participants of the first RCN Workshop 
(Seattle 2019). We thank the editor and two anonymous reviewers for their valuable comments that improved the manuscript.

\section{References cited}

Alberti M. 2005. The effects of urban patterns on ecosystem function. International Regional Science Review 28: 168-192.

Alberti M. 2008. Advances in Urban Ecology: Integrating Humans and Ecological Processes in Urban Ecosystems. Springer.

Alberti M. 2015. Eco-evolutionary dynamics in an urbanizing planet. Trends in Ecology and Evolution 30: 114-126.

Alberti M. 2016. Cities that Think Like Planets: Complexity, Resilience, and Innovation in Hybrid Ecosystems. University of Washington Press.

Alberti M, Botsford E, Cohen A. 2001. Quantifying the urban gradient: Linking urban planning and ecology. Pages $89-115$ in Marzluff JM, Bowman R, Donnelly R, eds. Avian Ecology and Conservation in an Urbanizing World. Springer.

Alberti M, Correa C, Marzluff JM, Hendry AP, Palkovacs EP, Gotanda KM, Hunt VM, Apgar TM, Zhou Y. 2017a. Global urban signatures of phenotypic change in animal and plant populations. Proceedings of the National Academy of Sciences 114: 8951-8956.

Alberti M, Marzluff J, Hunt VM. 2017b. Urban driven phenotypic changes: Empirical observations and theoretical implications for eco-evolutionary feedback. Philosophical Transactions of the Royal Society B 372: 20160029

Alberti M, Marzluff JM, Shulenberger E, Bradley G, Ryan C, Zumbrunnen C. 2003. Integrating humans into Ecology: Opportunities and challenges for studying urban ecosystems. BioScience 53: 1169-1179.

Alberti M, McPhearson T, Gonzalez A. 2018. Embracing urban complexity. Pages 45-67 in Elmqvist T, et al., eds. The Urban Planet: Knowledge towards Sustainable Cities. Cambridge University Press.

Alexander JM, Diez JM, Levine JM. 2015. Novel competitors shape species' responses to climate change. Nature 525: 515-518.

Alexander TJ, Vonlanthen P, Seehausen O. 2017. Does eutrophicationdriven evolution change aquatic ecosystems? Philosophical Transactions of the Royal Society B 372: 20160041 .

Allen CR, Holling CS. 2002. Cross-scale structure and scale breaks in ecosystems and other complex systems. Ecosystems 5: 315-318.

Aronson MFJ, et al. 2014. A global analysis of the impacts of urbanization on bird and plant diversity reveals key anthropogenic drivers. Proceedings of the Royal Society B 281: 20133330.

Atwell JW, Cardoso GC, Whittaker DJ, Campbell-Nelson S, Robertson KW Ketterson ED. 2012. Boldness behavior and stress physiology in a novel urban environment suggest rapid correlated evolutionary adaptation. Behavioral Ecology 23: 960-969.

Band LE, Cadenasso ML, Grimmond CS, Grove JM, Pickett STA. 2005. Heterogeneity in urban ecosystems: Patterns and process. Pages 257278 in Lovett GM, Turner MG, Jones CG, Weathers KC, eds. Ecosystem Function in Heterogeneous Landscapes. Springer.

Barrett RDH, Schluter D. 2008. Adaptation from standing genetic variation. Trends in Ecology and Evolution 23: 38-44.

Becker DJ, Streicker DG, Altizer S. 2015. Linking anthropogenic resources to wildlife-pathogen dynamics: A review and meta-analysis. Ecology Letters 18: 483-495.

Bell G. 2017. Evolutionary Rescue. Annual Review of Ecology, Evolution, and Systematics 48: 605-627.

Beninde J, Feldmeier S, Veith M, Hochkirch A. 2018. Admixture of hybrid swarms of native and introduced lizards in cities is determined by the cityscape structure and invasion history. Proceedings of the Royal Society B 285: 20180143.

Björklund M, Ruiz I, Senar JC. 2010. Genetic differentiation in the urban habitat: The great tits (Parus major) of the parks of Barcelona city. Biological Journal of the Linnean Society 99: 9-19.

Boivin NL, Zeder MA, Fuller DQ, Crowther A, Larson G, Erlandson JM, Denham T, Petraglia MD. 2016. Ecological consequences of human niche construction: Examining long-term anthropogenic shaping of global species distributions. Proceedings of the National Academy of Sciences 113: 6388-6396.

Bolchoun L, Drossel B, Allhoff KT. 2017. Spatial topologies affect local food web structure and diversity in evolutionary metacommunities. Scientific Reports 7: 1818.

Bolnick DI, Amarasekare P, Araújo MS, Bürger R, Levine JM, Novak M, Rudolf VHW, Schreiber SJ, Urban MC, Vasseur DA. 2011. Why intraspecific trait variation matters in community ecology. Trends in Ecology and Evolution 26: 183-192.

Brans KI, Govaert L, De Meester L. 2020. Evolutionary dynamics of metacommunities in urbanized landscapes. Pages $175-196$ in Szulkin M, Munshi-South J, Charmantier A, eds. Urban Evolutionary Biology. Oxford University Press.

Brans KI, Govaert L, Engelen JMT, Gianuca AT, Souffreau C, De Meester L. 2017a. Eco-evolutionary dynamics in urbanized landscapes: Evolution, species sorting and the change in zooplankton body size along urbanization gradients. Philosophical Transactions of the Royal Society B 372: 20160030

Brans KI, Jansen M, Vanoverbeke J, Tüzün N, Stoks R, De Meester L. 2017b. The heat is on: Genetic adaptation to urbanization mediated by thermal tolerance and body size. Global Change Biology 23: 5218-5227.

Brunner FS, Deere JA, Egas M, Eizaguirre C, Raeymaekers JAM. 2019. The diversity of eco-evolutionary dynamics: Comparing the feedbacks between ecology and evolution across scales. Functional Ecology 33: 7-12.

Bullock JM, Bonte D, Pufal G, da Silva Carvalho C, Chapman DS, García C, García D, Matthysen E, Delgado MM. 2018. Human-mediated dispersal and the rewiring of spatial networks. Trends in Ecology and Evolution 33: 958-970.

Cadenasso ML, Pickett STA, Grove JM. 2006. Dimensions of ecosystem complexity: Heterogeneity, connectivity, and history. Ecological Complexity 3: 1-12.

Cadenasso ML, Pickett STA, McGrath B, Marshall V. 2013. Ecological heterogeneity in urban ecosystems: Reconceptualized land cover models as a bridge to urban design. Pages 107-129 in Pickett STA, Cadenasso ML, McGrath B, eds. Resilience in Ecology and Urban Design: Linking Theory and Practice for Sustainable Cities. Springer.

Cadenasso ML, Pickett STA, Schwarz K. 2007. Spatial heterogeneity in urban ecosystems: Reconceptualizing land cover and a framework for classification. Frontiers in Ecology and the Environment 5: $80-88$

Campbell-Staton SC, Winchell KM, Rochette NC, Fredette J, Maayan I, Schweizer RM, Catchen J. 2020. Parallel selection on thermal physiology facilitates repeated adaptation of city lizards to urban heat islands. Nature Ecology and Evolution 4: 652-658.

Carlson SM, Quinn TP, Hendry AP. 2011. Eco-evolutionary dynamics in Pacific salmon. Heredity 106: 438.

Carroll SP. 2011. Conciliation biology: The eco-evolutionary management of permanently invaded biotic systems. Evolutionary Applications 4: 184-199.

Cavender-Bares J, Ackerly DD, Hobbie SE, Townsend PA. 2016. Evolutionary legacy effects on ecosystems: Biogeographic origins, plant traits, and implications for management in the era of global change. Annual Review of Ecology, Evolution, and Systematics 47: 433-462.

Cheptou P-O, Carrue O, Rouifed S, Cantarel A. 2008. Rapid evolution of seed dispersal in an urban environment in the weed Crepis sancta. Proceedings of the National Academy of Sciences 105: 3796-3799

Clarke LW, Jenerette GD, Davila A. 2013. The luxury of vegetation and the legacy of tree biodiversity in Los Angeles, CA. Landscape and Urban Planning 116: 48-59.

Cleland EE, Chuine I, Menzel A, Mooney HA, Schwartz MD. 2007. Shifting plant phenology in response to global change. Trends in Ecology and Evolution 22: 357-365.

Coldsnow KD, Mattes BM, Hintz WD, Relyea RA. 2016. Rapid evolution of tolerance to road salt in zooplankton. Environmental Pollution 30: 1e7. 
Collins SL, et al. 2011. An integrated conceptual framework for long-term social-ecological research. Frontiers in Ecology and the Environment 9: 351-357.

Cox DTC, Gaston KJ. 2018. Human-nature interactions and the consequences and drivers of provisioning wildlife. Philosophical Transactions of the Royal Society B 373: 20170092.

Dakos V, Matthews B, Hendry AP, Levine J, Loeuille N, Norberg J, Nosil P, Scheffer M, De Meester L. 2019. Ecosystem tipping points in an evolving world. Nature Ecology and Evolution 3: 355-362.

Dakos V, Van de Leemput I, Scheffer M, van Nes EH. 2018. Slow recovery from local disturbances as an indicator for loss of ecosystem resilience. Ecosystems 21: 141-152.

De Meester L, Brans KI, Govaert L, Souffreau C, Mukherjee S, Vanvelk H, Korzeniowski K, Kilsdonk L, Decaestecker E, Stoks R, Urban MC. 2019. Analysing eco-evolutionary dynamics: The challenging complexity of the real world. Functional Ecology 33: 43-59.

De Meester L, Vanoverbeke J, Kilsdonk LJ, Urban MC. 2016. Evolving perspectives on monopolization and priority effects. Trends in Ecology and Evolution 31: 136-146.

DeCandia AL, Brzeski KE, Heppenheimer E, Caro CV, Camenisch G Wandeler P, Driscoll C, vonHoldt BM. 2019a. Urban colonization through multiple genetic lenses: The city-fox phenomenon revisited. Ecology and Evolution 9: 2046-2060.

DeCandia AL, Henger CS, Krause A, Gormezano LJ, Weckel M, Nagy C, Munshi-South J, vonHoldt BM. 2019b. Genetics of urban colonization: Neutral and adaptive variation in coyotes (Canis latrans) inhabiting the New York metropolitan area. Journal of Urban Ecology 5: juz002.

Des Roches S, Post DM, Turley NE, Bailey JK, Hendry AP, Kinnison MT, Schweitzer JA, Palkovacs EP. 2018. The ecological importance of intraspecific variation. Nature Ecology and Evolution 2: 57-64.

Des Roches S, et al. Forthcoming. Socio-eco-evolutionary dynamics in cities. Evolutionary Applications.

Díaz S, et al. 2018. Assessing nature's contributions to people. Science 359: 270-272.

Donihue CM, Lambert MR. 2015. Adaptive evolution in urban ecosystems. AMBIO 44: 194-203.

Ellis EC. 2015. Ecology in an anthropogenic biosphere. Ecological Monographs 85: 287-331.

Elmore AJ, Kaushal SS. 2008. Disappearing headwaters: Patterns of stream burial due to urbanization. Frontiers in Ecology and the Environment 6: $308-312$.

Faassen EJ, Veraart AJ, Nes EHV, Dakos V, Lürling M, Scheffer M. 2015. Hysteresis in an experimental phytoplankton population. Oikos 124: $1617-1623$.

Faeth SH, Warren PS, Shochat E, Marussich WA. 2005. Trophic Dynamics in Urban Communities. BioScience 55: 399-407.

Faillace CA, Morin PJ. 2016. Evolution alters the consequences of invasions in experimental communities. Nature Ecology and Evolution 1: 1-7.

Fan C, Johnston M, Darling L, Scott L, Liao FH. 2019. Land use and socio-economic determinants of urban forest structure and diversity. Landscape and Urban Planning 181: 10-21.

Fenderson LE, Kovach AI, Llamas B. 2020. Spatiotemporal landscape genetics: Investigating ecology and evolution through space and time. Molecular Ecology 29: 218-246.

Findlay CST, Bourdages J. 2000. Response time of wetland biodiversity to road construction on adjacent lands. Conservation Biology 14: 86-94.

Fischer JD, Cleeton SH, Lyons TP, Miller JR. 2012. Urbanization and the predation paradox: The role of trophic dynamics in structuring vertebrate communities. BioScience 62: 809-818.

Fitzpatrick CR, Agrawal AA, Basiliko N, Hastings AP, Isaac ME, Preston M, Johnson MTJ. 2015. The importance of plant genotype and contemporary evolution for terrestrial ecosystem processes. Ecology 96: 2632-2642.

Fukami T. 2015. Historical contingency in community assembly: Integrating niches, species pools, and priority effects. Annual Review of Ecology, Evolution, and Systematics 46: 1-23.
Fukami T, Beaumont HJE, Zhang X-X, Rainey PB. 2007. Immigration history controls diversification in experimental adaptive radiation. Nature 446: 436-439.

Fussmann GF, Loreau M, Abrams PA. 2007. Eco-evolutionary dynamics of communities and ecosystems. Functional Ecology 21: 465-477.

Ger KA, Hansson L-A, Lürling M. 2014. Understanding cyanobacteria-zooplankton interactions in a more eutrophic world. Freshwater Biology 59: 1783-1798.

Govaert L, Fronhofer EA, Lion S, Eizaguirre C, Bonte D, Egas M, Hendry AP, De Brito Martins A, Melián CJ, Raeymaekers JA. 2019. Eco-evolutionary feedbacks-Theoretical models and perspectives. Functional Ecology 33: 13-30.

Govaert L, Pantel JH, De Meester L. 2016. Eco-evolutionary partitioning metrics: Assessing the importance of ecological and evolutionary contributions to population and community change. Ecology Letters 19: 839-853.

Grimm NB, Faeth SH, Golubiewski NE, Redman CL, Wu J, Bai X, Briggs JM. 2008. Global change and the ecology of cities. Science 319: 756-760.

Grimm NB, Pickett STA, Hale RL, Cadenasso ML. 2017. Does the ecological concept of disturbance have utility in urban social-ecological-technological systems? Ecosystem Health and Sustainability 3: e01255.

Groffman PM, et al. 2014. Ecological homogenization of urban USA. Frontiers in Ecology and the Environment 12: 74-81.

Grove M, Ogden L, Pickett S, Boone C, Buckley G, Locke DH, Lord C, Hall B. 2018. The legacy effect: Understanding how segregation and environmental injustice unfold over time in Baltimore. Annals of the American Association of Geographers 108: 524-537.

Hahs AK, McDonnell MJ, McCarthy MA, Vesk PA, Corlett RT, Norton BA, Clemants SE, Duncan RP, Thompson K, Schwartz MW, Williams NSG. 2009. A global synthesis of plant extinction rates in urban areas. Ecology Letters 12: 1165-1173.

Hairston NG, Holtmeier CL, Lampert W, Weider LJ, Post DM, Fischer JM, Cáceres CE, Fox JA, Gaedke U. 2001. Natural selection for grazer resistance to toxic cyanobacteria: Evolution of phenotypic plasticity? Evolution 55: 2203-2214.

Helm B, Ben-Shlomo R, Sheriff MJ, Hut RA, Foster R, Barnes BM, Dominoni D. 2013. Annual rhythms that underlie phenology: Biological time-keeping meets environmental change. Proceedings of the Royal Society B 280: 20130016

Hendry AP. 2016. Eco-evolutionary Dynamics. Princeton University Press.

Hendry AP. 2019. A critique for eco-evolutionary dynamics. Functional Ecology 33: 84-94.

Hendry AP, Gotanda KM, Svensson EI. 2017. Human influences on evolution, and the ecological and societal consequences. Philosophical Transactions of the Royal Society B 372: 20160028.

Henger CS, Herrera GA, Nagy CM, Weckel ME, Gormezano LJ, Wultsch C, Munshi-South J. 2019. Genetic diversity and relatedness of a recently established population of eastern coyotes (Canis latrans) in New York City. Urban Ecosystems. 1-12.

Hiltunen T, Virta M, Laine A-L. 2017. Antibiotic resistance in the wild: An eco-evolutionary perspective. Philosophical Transactions of the Royal Society B 372: 20160039.

Holling CS. 1973. Resilience and stability of ecological systems. Annual Review of Ecology and Systematics 4: 1-23.

Holling CS. 1992. Cross-scale morphology, geometry, and dynamics of ecosystems. Ecological Monographs 62: 447-502.

Huang G, Cadenasso ML. 2016. People, landscape, and urban heat island: Dynamics among neighborhood social conditions, land cover and surface temperatures. Landscape Ecology 31: 2507-2515.

Hutchinson GE. 1965. The Ecological Theater and the Evolutionary Play. Yale University Press.

Jenerette GD, Harlan SL, Stefanov WL, Martin CA. 2011. Ecosystem services and urban heat riskscape moderation: Water, green spaces, and social inequality in Phoenix, USA. Ecological Applications 21: $2637-2651$. 
Johnson MTJ, Munshi-South J. 2017. Evolution of life in urban environments. Science 358: eaam8327.

Kaye JP, Groffman PM, Grimm NB, Baker LA, Pouyat RV. 2006. A distinct urban biogeochemistry? Trends in Ecology and Evolution 21: 192-199.

Kettlewell HD. 1958. A survey of the frequencies of Biston betularia (L.)(Lep.) and its melanic forms in Great Britain. Heredity 12: 51-72.

Kille P, Andre J, Anderson C, Ang HN, Bruford MW, Bundy JG, Donnelly R, Hodson ME, Juma G, Lahive E. 2013. DNA sequence variation and methylation in an arsenic tolerant earthworm population. Soil Biology and Biochemistry 57: 524-532.

Kille P, Sturzenbaum SR, Galay M, Winters C, Morgan AJ. 1999. Molecular diagnosis of pollution impact in earthworms: Towards integrated biomonitoring. Pedobiologia 43: 602-607.

Kinnison MT, Hairston Jr NG. 2007. Eco-evolutionary conservation biology: Contemporary evolution and the dynamics of persistence. Functional Ecology 21: 444-454.

Kinnison MT, Hairston NG, Hendry AP. 2015. Cryptic eco-evolutionary dynamics: Cryptic eco-evolutionary dynamics. Annals of the New York Academy of Sciences 1360: 120-144.

Ksiazek-Mikenas K, Fant JB, Skogen KA. 2019. Pollinator-mediated gene flow connects green roof populations across the urban matrix: A paternity analysis of the self-compatible forb Penstemon hirsutus. Frontiers in Ecology and Evolution 7: 299.

Kuras ER, Warren PS, Zinda JA, Aronson MFJ, Cilliers S, Goddard MA, Nilon CH, Winkler R. 2020. Urban socio-economic inequality and biodiversity often converge, but not always: A global meta-analysis. Landscape and Urban Planning 198: 103799.

Lambert MR, Donihue CM. 2020. Urban biodiversity management using evolutionary tools. Nature Ecology and Evolution 4, 903-910.

Leibold MA, Holyoak M, Mouquet N, Amarasekare P, Chase JM, Hoopes MF, Holt RD, Shurin JB, Law R, Tilman D. 2004. The metacommunity concept: A framework for multi-scale community ecology. Ecology letters 7: 601-613.

Leibold MA, Urban MC, De Meester L, Klausmeier CA, Vanoverbeke J. 2019. Regional neutrality evolves through local adaptive niche evolution. Proceedings of the National Academy of Sciences 116: 2612-2617.

Leong M, Dunn RR, Trautwein MD. 2018. Biodiversity and socio-economics in the city: A review of the luxury effect. Biology Letters 14: 20180082.

Levin SA, et al.. 1998. Resilience in natural and socio-economic systems. Environment and Development Economics 3: 221-262.

Levin SA, Paine RT. 1974. Disturbance, patch formation, and community structure. Proceedings of the National Academy of Sciences 71: 2744-2747.

Li X, Zhou Y, Asrar GR, Mao J, Li X, Li W. 2017. Response of vegetation phenology to urbanization in the conterminous United States. Global Change Biology 23: 2818-2830.

Liu H, Liu S, Xue B, Lv Z, Meng Z, Yang X, Xue T, Yu Q, He K. 2018. Groundlevel ozone pollution and its health impacts in China. Atmospheric Environment 173: 223-230.

Liu J, et al.. 2007. Complexity of Coupled Human and Natural Systems. Science 317: 1513-1516.

Liu J, Yang W, Li S. 2016a. Framing ecosystem services in the telecoupled Anthropocene. Frontiers in Ecology and the Environment 14: $27-36$.

Liu Z, He C, Wu J. 2016b. The relationship between habitat loss and fragmentation during urbanization: An empirical evaluation from 16 world cities. PLOS ONE 11: 0154613.

Loreau M, Mouquet N, Gonzalez A. 2003. Biodiversity as spatial insurance in heterogeneous landscapes. Proceedings of the National Academy of Sciences 100: 12765-12770.

Lundholm J. 2015. The ecology and evolution of constructed ecosystems as green infrastructure. Frontiers in Ecology and Evolution 3: 106.

Machlis GE, Force JE, JR WRB. 1997. The human ecosystem, part I: The human ecosystem as an organizing concept in ecosystem management. Society and Natural Resources 10: 347-367.
Manel S, Holderegger R. 2013. Ten years of landscape genetics. Trends in Ecology and Evolution 28: 614-621.

Martínez-Abraín A, Jiménez J, Oro D. 2019. Pax Romana: "Refuge abandonment" and spread of fearless behavior in a reconciling world. Animal Conservation 22: 3-13.

Marzluff JM. 2008. Island biogeography for an urbanizing world how extinction and colonization may determine biological diversity in humandominated landscapes. Pages 355-371 in Marzluff JM, Shulenberger E, Endlicher W, Alberti M, Bradley G, Ryan C, Simon U, ZumBrunnen C, eds. Urban Ecology: An International Perspective on the Interaction Between Humans and Nature. Springer.

Matthews B, et al. 2011. Toward an integration of evolutionary biology and ecosystem science. Ecology Letters 14: 690-701.

McDonnell MJ, Hahs AK. 2008. The use of gradient analysis studies in advancing our understanding of the ecology of urbanizing landscapes: Current status and future directions. Landscape Ecology 23: 1143-1155.

McDonnell MJ, Hahs AK. 2015. Adaptation and adaptedness of organisms to urban environments. Annual Review of Ecology, Evolution, and Systematics 46: 261-280.

McDonnell MJ, Pickett ST. 1993. Humans as Components of Ecosystems The Ecology of Subtle Human Effects and Populated Areas. Springer.

McPhearson T, Pickett STA, Grimm NB, Niemelä J, Alberti M, Elmqvist T, Weber C, Haase D, Breuste J, Qureshi S. 2016. Advancing Urban Ecology toward a Science of Cities. BioScience 66: 198-212.

Mellard JP, de Mazancourt C, Loreau M. 2015. Evolutionary responses to environmental change: Trophic interactions affect adaptation and persistence. Proceedings of the Royal Society B 282: 20141351.

Merckx T, et al. 2018. Body-size shifts in aquatic and terrestrial urban communities. Nature 558: 113-116.

Merilä J, Hendry AP. 2014. Climate change, adaptation, and phenotypic plasticity: The problem and the evidence. Evolutionary Applications 7: 1-14.

Miles LS, Johnson JC, Dyer RJ, Verrelli BC. 2018. Urbanization as a facilitator of gene flow in a human health pest. Molecular Ecology 27: 3219-3230.

Miles LS, Rivkin LR, Johnson MTJ, Munshi-South J, Verrelli BC. 2019. Gene flow and genetic drift in urban environments. Molecular Ecology 28: 4138-4151.

Miner BE, De Meester L, Pfrender ME, Lampert W, Hairston Jr NG. 2012. Linking genes to communities and ecosystems: Daphnia as an ecogenomic model. Proceedings of the Royal Society B 279: 1873-1882.

Munshi-South J, Zak Y, Pehek E. 2013. Conservation genetics of extremely isolated urban populations of the northern dusky salamander (Desmognathus fuscus) in New York City. PeerJ 1: e64.

Munshi-South J, Zolnik CP, Harris SE. 2016. Population genomics of the Anthropocene: Urbanization is negatively associated with genome-wide variation in white-footed mouse populations. Evolutionary Applications 9: 546-564.

Murray MH, Sánchez CA, Becker DJ, Byers KA, Worsley-Tonks KE, Craft ME. 2019. City sicker? A meta-analysis of wildlife health and urbanization. Frontiers in Ecology and the Environment 17: 575-583.

Nacci DE, Champlin D, Jayaraman S. 2010. Adaptation of the estuarine fish Fundulus heteroclitus (Atlantic killifish) to polychlorinated biphenyls (PCBs). Estuaries and Coasts 33: 853-864.

Narango DL, Tallamy DW, Marra PP. 2018. Nonnative plants reduce population growth of an insectivorous bird. Proceedings of the National Academy of Sciences 115: 11549-11554.

Newsome TM, Dellinger JA, Pavey CR, Ripple WJ, Shores CR, Wirsing AJ, Dickman CR. 2015. The ecological effects of providing resource subsidies to predators. Global Ecology and Biogeography 24: 1-11.

Norberg J, Urban MC, Vellend M, Klausmeier CA, Loeuille N. 2012. Eco-evolutionary responses of biodiversity to climate change. Nature Climate Change 2: 747.

Odling-Smee J, Erwin DH, Palkovacs EP, Feldman MW, Laland KN. 2013. Niche construction theory: A practical guide for ecologists. Quarterly Review of Biology 88: 3-28. 
O’Neill RV, Deangelis DL, Waide JB, Allen TFH, Allen GE. 1986. A Hierarchical Concept of Ecosystems. Princeton University Press.

Oro D, Genovart M, Tavecchia G, Fowler MS, Martínez-Abraín A. 2013. Ecological and evolutionary implications of food subsidies from humans. Ecology Letters 16: 1501-1514.

Palkovacs EP, Dion KB, Post DM, Caccone A. 2008. Independent evolutionary origins of landlocked alewife populations and rapid parallel evolution of phenotypic traits. Molecular Ecology 17: 582-597.

Palkovacs EP, Hendry AP. 2010. Eco-evolutionary dynamics: Intertwining ecological and evolutionary processes in contemporary time. F1000 Biology Reports 2: 1.

Palkovacs EP, Kinnison MT, Correa C, Dalton CM, Hendry AP. 2012. Fates beyond traits: Ecological consequences of human-induced trait change. Evolutionary Applications 5: 183-191.

Palkovacs EP, Post DM. 2009. Experimental evidence that phenotypic divergence in predators drives community divergence in prey. Ecology 90: 300-305.

Pantel JH, Duvivier C, De Meester L. 2015. Rapid local adaptation mediates zooplankton community assembly in experimental mesocosms. Ecology Letters 18: 992-1000.

Partecke J. 2013. Mechanisms of phenotypic responses following colonization of urban areas: From plastic to genetic adaptation. Pages 131-142 in Gil D, Brumm H, eds. Avian Urban Ecology. Behavioural, and Physiological Adaptations. Oxford University Books.

Pearse WD, et al. 2018. Homogenization of plant diversity, composition, and structure in North American urban yards. Ecosphere 9: e02105.

Perrier C, Campo AL del, Szulkin M, Demeyrier V, Gregoire A, Charmantier A. 2018. Great tits and the city: Distribution of genomic diversity and gene-environment associations along an urbanization gradient. Evolutionary Applications 11: 593-613.

Peters DPC, Bestelmeyer BT, Turner MG. 2007. Cross-scale interactions and changing pattern-process relationships: Consequences for system dynamics. Ecosystems 10: 790-796.

Peters DPC, et al. 2018. An integrated view of complex landscapes: A big data-model integration approach to transdisciplinary science. BioScience 68: 653-669.

Piano E, et al. 2017. Urbanization drives community shifts towards thermophilic and dispersive species at local and landscape scales. Global Change Biology 23: 2554-2564.

Pickett STA, Burch WR, Dalton SE, Foresman TW, Grove JM, Rowntree R. 1997. A conceptual framework for the study of human ecosystems in urban areas. Urban Ecosystems 1: 185-199.

Pickett STA, Cadenasso ML, Childers DL, Mcdonnell MJ, Zhou W. 2016. Evolution and future of urban ecological science: Ecology in, of, and for the city. Ecosystem Health and Sustainability 2: e01229.

Pickett STA, Cadenasso ML, Grove JM, Nilon CH, Pouyat RV, Zipperer WC, Costanza R. 2001. Urban ecological systems: Linking terrestrial ecological, physical, and socio-economic components of metropolitan areas. Annual Review of Ecology and Systematics 32: 127-157.

Post DM, Palkovacs EP. 2009. Eco-evolutionary feedbacks in community and ecosystem ecology: Interactions between the ecological theatre and the evolutionary play. Philosophical Transactions of the Royal Society B 364: 1629-1640.

Post DM, Palkovacs EP, Schielke EG, Dodson SI. 2008. Intraspecific variation in a predator affects community structure and cascading trophic interactions. Ecology 89: 2019-2032.

Preiser R, Biggs R, De Vos A, Folke C. 2018. Social-ecological systems as complex adaptive systems: Organizing principles for advancing research methods and approaches. Ecology and Society 23: 46.

Rebele F. 1994. Urban ecology and special features of urban ecosystems. Global Ecology and Biogeography Letters 4: 173-187.

Rivkin LR, et al. 2019. A roadmap for urban evolutionary ecology. Evolutionary Applications 12: 384-398.

Rodewald AD, Kearns LJ, Shustack DP. 2011. Anthropogenic resource subsidies decouple predator-prey relationships. Ecological Applications 21: 936-943.
Roman LA, Pearsall H, Eisenman TS, Conway TM, Fahey RT, Landry S, Vogt J, van Doorn NS, Grove JM, Locke DH. 2018. Human and biophysical legacies shape contemporary urban forests: A literature synthesis. Urban Forestry and Urban Greening 31: 157-168.

Rossberg AG, Matsuda H, Amemiya T, Itoh K. 2006. Food webs: Experts consuming families of experts. Journal of Theoretical Biology 241: 552-563.

Rudd H, Vala J, Schaefer V. 2002. Importance of backyard habitat in a comprehensive biodiversity conservation strategy: A connectivity analysis of urban green spaces. Restoration Ecology 10: 368-375.

Rudman SM, Rodriguez-Cabal MA, Stier A, Sato T, Heavyside J, El-Sabaawi RW, Crutsinger GM. 2015. Adaptive genetic variation mediates bottomup and top-down control in an aquatic ecosystem. Proceedings of the Royal Society B 282: 20151234.

Santangelo JS, Miles LS, Breitbart ST, Murray-Stoker D, Rivkin LR, Johnson MTJ, Ness RW. 2020. Urban environments as a framework to study parallel evolution. Pages 36-53 in Szulkin M, Munshi-South J, Charmantier A, eds. Urban Evolutionary Biology. Oxford University Press.

Satgé J de, Strubbe D, Elst J, Laet JD, Adriaensen F, Matthysen E. 2019. Urbanisation lowers great tit Parus major breeding success at multiple spatial scales. Journal of Avian Biology 50: 2108.

Scheffer M, Carpenter S, Foley JA, Folke C, Walker B. 2001. Catastrophic shifts in ecosystems. Nature 413: 591-596.

Schoener TW. 2011. The newest synthesis: Understanding the interplay of evolutionary and ecological dynamics. Science 331: 426-429.

Schwarz K, Fragkias M, Boone CG, Zhou W, McHale M, Grove JM, O’NeilDunne J, McFadden JP, Buckley GL, Childers D. 2015. Trees grow on money: Urban tree canopy cover and environmental justice. PLOS ONE 10: $\mathrm{e} 0122051$.

Smith TB, Kinnison MT, Strauss SY, Fuller TL, Carroll SP. 2014. Prescriptive evolution to conserve and manage biodiversity. Annual Review of Ecology, Evolution, and Systematics 45: 1-22.

Somers CM, McCarry BE, Malek F, Quinn JS. 2004. Reduction of particulate air pollution lowers the risk of heritable mutations in mice. Science 304: 1008-1010.

Soranno PA, Cheruvelil KS, Bissell EG, Bremigan MT, Downing JA, Fergus CE, Filstrup CT, Henry EN, Lottig NR, Stanley EH, Stow CA, Tan P-N, Wagner T, Webster KE. 2014. Cross-scale interactions: Quantifying multi-scaled cause-effect relationships in macrosystems. Frontiers in Ecology and the Environment 12: 65-73.

Soulsbury CD, White PCL. 2016. Human-wildlife interactions in urban areas: A review of conflicts, benefits and opportunities. Wildlife Research 42: 541-553.

Start D, Barbour MA, Bonner C. 2019. Urbanization reshapes a food web. Journal of Animal Ecology 89: 808-816.

Sukopp H. 1990. Urban ecology and its application in Europe. Pages 1-22 in Sukopp H, ed. Urban Ecology. SPB Academic.

Suraci JP, Clinchy M, Zanette LY, Wilmers CC. 2019. Fear of humans as apex predators has landscape-scale impacts from mountain lions to mice. Ecology Letters 22: 1578-1586.

Szulkin M, Garroway CJ, Corsini M, Kotarba AZ, Dominoni D. 2020. How to quantify urbanisation when testing for urban evolution? Pages 13-35 in Szulkin M, Munshi-South J, Charmantier A, eds. Urban Evolutionary Biology. Oxford University Press.

Szulkin M, Munshi-South J, Charmantier A, eds. 2020. Urban Evolutionary Biology. Oxford University Press.

terHorst CP, Zee PC. 2016. Eco-evolutionary dynamics in plant-soil feedbacks. Functional Ecology 30: 1062-1072.

Thompson PL, Fronhofer EA. 2019. The conflict between adaptation and dispersal for maintaining biodiversity in changing environments. Proceedings of the National Academy of Sciences 116: 21061-21067.

Toju H, Yamamichi M, Guimaraes Jr PR, Olesen JM, Mougi A, Yoshida T, Thompson JN. 2017. Species-rich networks and eco-evolutionary synthesis at the metacommunity level. Nature Ecology and Evolution 1: 0024 . 
Urban MC, De Meester L. 2009. Community monopolization: Local adaptation enhances priority effects in an evolving metacommunity. Proceedings of the Royal Society B 276: 4129-4138.

Urban MC, De Meester L, Vellend M, Stoks R, Vanoverbeke J. 2012. A crucial step toward realism: Responses to climate change from an evolving metacommunity perspective. Evolutionary Applications 5: 154-167.

Urban MC, et al. 2008. The evolutionary ecology of metacommunities. Trends in Ecology and Evolution 23: 311-317.

Urban MC, Skelly DK. 2006. Evolving metacommunities: Toward an evolutionary perspective on metacommunities. Ecology 87: $1616-1626$.

Wagener FO. 2003. Skiba points and heteroclinic bifurcations, with applications to the shallow lake system. Journal of Economic Dynamics and Control 27: 1533-1561.

Walker JS, Grimm NB, Briggs JM, Gries C, Dugan L. 2009. Effects of urbanization on plant species diversity in central Arizona. Frontiers in Ecology and the Environment 7: 465-470.

Walsh MR, DeLong JP, Hanley TC, Post DM. 2012. A cascade of evolutionary change alters consumer-resource dynamics and ecosystem function. Proceedings of the Royal Society B 279: 3184-3192.

Wang C, Wang Z-H, Wang C, Myint SW. 2019. Environmental cooling provided by urban trees under extreme heat and cold waves in U.S. cities. Remote Sensing of Environment 227: 28-43.

Weber MG, Wagner CE, Best RJ, Harmon LJ, Matthews B. 2017. Evolution in a community context: On integrating ecological interactions and macroevolution. Trends in Ecology and Evolution 32: 291-304.

Wei C, Padgham M, Cabrera Barona P, Blaschke T. 2017. Scale-free relationships between social and landscape factors in urban systems. Sustainability 9: 84 .

Whitehead A, Triant DA, Champlin D, Nacci D. 2010. Comparative transcriptomics implicates mechanisms of evolved pollution tolerance in a killifish population. Molecular Ecology 19: 5186-5203.

Whittaker RH. 1967. Gradient analysis of vegetation. Biological Reviews 42: 207-264.

Wu J, Loucks OL. 1995. From balance of nature to hierarchical patch dynamics: A paradigm shift in ecology. Quarterly Review of Biology 70: 439-466.

Yauk CL, Fox GA, McCarry BE, Quinn JS. 2000. Induced minisatellite germline mutations in herring gulls (Larus argentatus) living near steel mills. Mutation Research/Fundamental and Molecular Mechanisms of Mutagenesis 452: 211-218.
Yeh PJ, Price TD. 2004. Adaptive Phenotypic Plasticity and the Successful Colonization of a Novel Environment. The American Naturalist 164: 531-542.

Zipperer W, Morse W, Gaither C. 2011. Linking social and ecological systems. Pages 298-308 in Niemela J, ed. Urban Ecology: Patterns, Processes, and Applications. Oxford University Press.

Ziter C, Graves RA, Turner MG. 2017. How do land-use legacies affect ecosystem services in United States cultural landscapes? Landscape Ecology 32: 2205-2218.

Marina Alberti is affiliated with the Department of Urban Design and Planning at the University of Washington, in Seattle, Washington. Eric P. Palkovacs is affiliated with the Department of Ecology and Evolutionary Biology at the University of California, Santa Cruz, California. Simone Des Roches is affiliated with the School of Aquatic and Fisheries Sciences at the University of Washington in Seattle, Washington. Luc De Meester and Kristien I. Brans are affiliated with the Laboratory of Aquatic Ecology Evolution, and Conservation, at Katholieke Universiteit Leuven, in Leuven, Belgium. LDM is also affiliated with the Leibniz Institut für Gewässerökologie und Binnenfischerei, in Berlin, Germany, and with the Institute of Biology at Freie Universität Berlin, also in Berlin, Germany. Lynn Govaert is affiliated with the Department of Evolutionary Biology and Environmental Studies at the University of Zurich, in Zurich, Switzerland; with the Department of Aquatic Ecology, in the Swiss Federal Institute of Aquatic Science and Technology, in Dübendorf, Switzerland; and with the University Research Priority Programme on Global Change and Biodiversity at the University of Zurich, in Zurich, Switzerland. Nancy B. Grimm is affiliated with the School of Life Sciences at Arizona State University, in Tempe, Arizona. Nyeema C. Harris is affiliated with the Applied Wildlife Ecology Lab, in the Department of Ecology and Evolutionary Biology at the University of Michigan, in Ann Arbor, Michigan. Andrew P. Hendry is affiliated with the Redpath Museum and with the Department of Biology at McGill University, in Montreal, Quebec, Canada. Christopher J. Schell is affiliated with the Department of Interdisciplinary Arts and Sciences at the University of Washington Tacoma, in Tacoma, Washington. Marta Szulkin is affiliated with the Centre of New Technologies at the University of Warsaw, in Warsaw, Poland. Jason MunshiSouth is affiliated with the Louis Calder Center Biological Field Station, at Fordham University, in Armonk, New York. Mark C. Urban is affiliated with the Center of Biological Risk and the Department of Ecology and Evolutionary Biology at the University of Connecticut, in Storrs, Connecticut. Brian C. Verrelli is affiliated with the Center for Life Sciences Education at Virginia Commonwealth University, in Richmond, Virginia. 